\title{
Strategies to improve recruitment to randomised controlled trials (Review)
}

Treweek S, Mitchell E, Pitkethly M, Cook J, Kjeldstrøm M, Taskila T, Johansen M, Sullivan F, Wilson S, Jackson C, Jones R

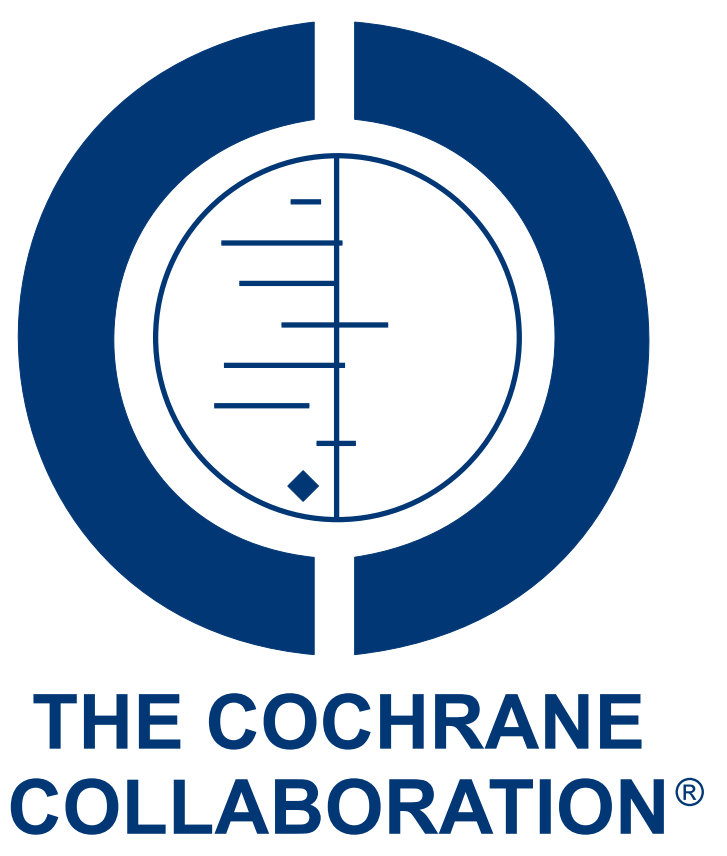

This is a reprint of a Cochrane review, prepared and maintained by The Cochrane Collaboration and published in The Cochrane Library 2010, Issue 1

http://www.thecochranelibrary.com

\section{WILEY}

Strategies to improve recruitment to randomised controlled trials (Review)

Copyright $\odot 2010$ The Cochrane Collaboration. Published by John Wiley \& Sons, Ltd. 
TABLE OF CONTENTS

HEADER . . . . . . . . . . . . . . . . . . . . . . . . . . . . . . . . . . . . . . . . . . . . . . . . .

ABSTRACT . . . . . . . . . . . . . . . . . . . . . . . . . . . . . . . . . . . . . . . . . . . . . . . . . . . .

PLAIN LANGUAGE SUMMARY . . . . . . . . . . . . . . . . . . . . . . . . . . . . . . . . . . . . . . . . . . .

BACKGROUND . . . . . . . . . . . . . . . . . . . . . . . . . . . . . . . . . . . . . 2

OBJECTIVES . . . . . . . . . . . . . . . . . . . . . . . . . . . . . . . . . . . . . . . . . . . . . . . . . . .

METHODS . . . . . . . . . . . . . . . . . . . . . . . . . . . . . . . . . . . . . . . 3

RESULTS . . . . . . . . . . . . . . . . . . . . . . . . . . . . . . . . . . . . . . . . . . .

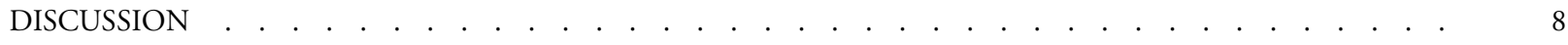

AUTHORS' CONCLUSIONS . . . . . . . . . . . . . . . . . . . . . . . . . . . . . . . . . . . . . . . . . .

ACKNOWLEDGEMENTS . . . . . . . . . . . . . . . . . . . . . . . . . . . . . . . . . . . . . . . . 10

REFERENCES . . . . . . . . . . . . . . . . . . . . . . . . . . . . . . . . . . . . . . 10

CHARACTERISTICS OF STUDIES . . . . . . . . . . . . . . . . . . . . . . . . . . . . . . . . . . . . . . . . .

DATA AND ANALYSES . . . . . . . . . . . . . . . . . . . . . . . . . . . . . . . . . . . . . . . . . . . . . . . . . . . 34

Analysis 1.1. Comparison 1 Open RCT vs Blinded RCT, Outcome 1 Participant recruited. . . . . . . . . . . 39

Analysis 2.1. Comparison 2 Placebo vs other comparator RCT, Outcome 1 Participant recruited. . . . . . . . . . . 40

Analysis 3.1. Comparison 3 Other change to trial design vs conventional RCT, Outcome 1 Participant recruited. . . 40

Analysis 4.1. Comparison 4 Opt-out consent vs opt-in consent, Outcome 1 Participant recruited. . . . . . . . . . 41

Analysis 5.1. Comparison 5 Consent to experimental care vs usual consent, Outcome 1 Participant recruited. . . . 41

Analysis 6.1. Comparison 6 Consent to standard care vs usual consent, Outcome 1 Participant recruited. . . . . . 42

Analysis 7.1. Comparison 7 Refusers choose treatment vs usual consent, Outcome 1 Participant recruited. . . . . . 42

Analysis 8.1. Comparison 8 Physician modified consent vs usual consent, Outcome 1 Participant recruited. . . . . . 43

Analysis 9.1. Comparison 9 Participant modified consent vs usual consent, Outcome 1 Participant recruited. . . . . 43

Analysis 10.1. Comparison 10 Educational video vs standard information, Outcome 1 Participant recruited. . . . . 44

Analysis 11.1. Comparison 11 Educational video + written information vs written information, Outcome 1 Participant recruited. . . . . . . . . . . . . . . . . . . . . . . . . . . . . . . . . . . .

Analysis 12.1. Comparison 12 Telephone screening vs face-to-face screening, Outcome 1 Participant recruited. . .

Analysis 13.1. Comparison 13 Enhanced recruitment package vs standard recruitment package, Outcome 1 Participant recruited.

Analysis 14.1. Comparison 14 Enhanced recruitment package + baseline data over'phone vs standard recruitment package, Outcome 1 Participant recruited.

Analysis 15.1. Comparison 15 Enhanced recruitment package + recruitment at churches vs standard recruitment package, Outcome 1 Participant recruited.

Analysis 16.1. Comparison 16 Electronic completion of screening questionnaire vs standard paper completion, Outcome 1 Participant recruited.

Analysis 17.1. Comparison 17 Oral completion of screening questionnaire vs standard paper completion, Outcome 1 Participant recruited.

Analysis 18.1. Comparison 18 Home safety questionnaire + trial invitation vs trial invitation, Outcome 1 Participant recruited.

Analysis 19.1. Comparison 19 Clinical trial booklet + standard information vs standard information, Outcome 1 Participant recruited.

Analysis 20.1. Comparison 20 Negative framing of side effects vs neutral framing, Outcome 1 Participant recruited. .

Analysis 21.1. Comparison 21 Positive framing of side effects vs neutral framing, Outcome 1 Participant recruited. .

Analysis 22.1. Comparison 22 Interactive computer presentation of trial information vs audio-taped presentation, Outcome 1 Participant recruited.

Analysis 23.1. Comparison 23 Writing treatment effect is 'twice as fast' in trial information vs writing 'half as fast', Outcome 1 Participant recruited.

Analysis 24.1. Comparison 24 Total information disclosure vs standard disclosure, Outcome 1 Participant recruited. 51

Analysis 25.1. Comparison 25 Telephone reminder vs no telephone reminder, Outcome 1 Participant recruited. . . 51

ADDITIONAL TABLES . . . . . . . . . . . . . . . . . . . . . . . . . . . . . . . . . . 51

APPENDICES . . . . . . . . . . . . . . . . . . . . . . . . . . . . . . . . . . . . . . . . . . . . . . 52

WHAT'S NEW . . . . . . . . . . . . . . . . . . . . . . . . . . . . . . . . . . . . . . . . . . . . . . . .

Strategies to improve recruitment to randomised controlled trials (Review)

Copyright $\odot 2010$ The Cochrane Collaboration. Published by John Wiley \& Sons, Ltd. 1

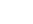

.


HISTORY . . . . . . . . . . . . . . . . . . . . . . . . . . . . . . . . . . . . . . . . . . . . . 60

CONTRIBUTIONS OF AUTHORS . . . . . . . . . . . . . . . . . . . . . . . . . . . . . . . . . . . . . . 61

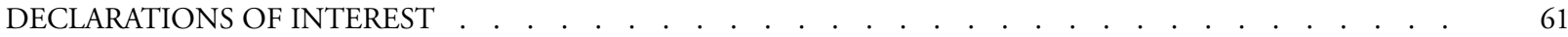

SOURCES OF SUPPORT . . . . . . . . . . . . . . . . . . . . . . . . . . . . . . . . . . . . . . . . . . . . . . . 61

DIFFERENCES BETWEEN PROTOCOL AND REVIEW . . . . . . . . . . . . . . . . . . . . . . . . . . . . . . . 61

INDEX TERMS . . . . . . . . . . . . . . . . . . . . . . . . . . . . . . . . . . . . 61 


\title{
[Methodology Review] \\ Strategies to improve recruitment to randomised controlled trials
}

\author{
Shaun Treweek ${ }^{1}$, Elizabeth Mitchell ${ }^{1}$, Marie Pitkethly ${ }^{2}$, Jonathan Cook $^{3}$, Monica Kjeldstrøm ${ }^{4}$, Taina Taskila ${ }^{5}$, Marit Johansen ${ }^{6}$, Frank \\ Sullivan $^{2}$, Sue Wilson ${ }^{7}$, Catherine Jackson ${ }^{8}$, Ritu Jones ${ }^{9}$ \\ ${ }^{1}$ Division of Clinical \& Population Sciences and Education, University of Dundee, Dundee, UK. ${ }^{2}$ Centre for Primary Care and \\ Population Research, Division of Clinical and Population Sciences and Education, University of Dundee, Dundee, UK. ${ }^{3} \mathrm{Health}$ \\ Services Research Unit, University of Aberdeen, Aberdeen, UK. ${ }^{4}$ Nordic Cochrane Centre, Rigshospitalet, Copenhagen, Denmark. \\ ${ }^{5}$ Department of Primary Care and General Practice, University of Birmingham, Birmingham, UK. ${ }^{6}$ Norwegian Knowledge Centre for \\ the Health Services, Oslo, Norway. ${ }^{7}$ Dept of Primary Care and General Practice, The Medical School, Birmingham, UK. ${ }^{8}$ Community \\ Health Sciences, Bute Medical School, St Andrews, UK. ${ }^{9}$ Division of Clinical \& Population Science and Education, University of \\ Dundee, Dundee, UK
}

Contact address: Shaun Treweek, Division of Clinical \& Population Sciences and Education, University of Dundee, Kirsty Semple Way, Dundee, DD2 4BF, UK. streweek@mac.com.

Editorial group: Cochrane Methodology Review Group.

Publication status and date: New search for studies and content updated (no change to conclusions), published in Issue 1, 2010.

Review content assessed as up-to-date: 6 October 2009.

Citation: Treweek S, Mitchell E, Pitkethly M, Cook J, Kjeldstrøm M, Taskila T, Johansen M, Sullivan F, Wilson S, Jackson C, Jones R. Strategies to improve recruitment to randomised controlled trials. Cochrane Database of Systematic Reviews 2010, Issue 1. Art. No.: MR000013. DOI: 10.1002/14651858.MR000013.pub4.

Copyright (C) 2010 The Cochrane Collaboration. Published by John Wiley \& Sons, Ltd.

\begin{abstract}
A B S T R A C T
Background

Recruiting participants to trials can be extremely difficult. Identifying strategies that improve trial recruitment would benefit both trialists and health research.
\end{abstract}

\section{Objectives}

To quantify the effects of strategies to improve recruitment of participants to randomised controlled trials.

\section{Search strategy}

We searched the Cochrane Methodology Review Group Specialised Register - CMR (The Cochrane Library (online) Issue 12008$)$ (searched 20 February 2008); MEDLINE, Ovid (1950 to date of search) (searched 06 May 2008); EMBASE, Ovid (1980 to date of search) (searched 16 May 2008); ERIC, CSA (1966 to date of search) (searched 19 March 2008); Science Citation Index Expanded, ISI Web of Science (1975 to date of search) (searched 19 March 2008); Social Sciences Citation Index, ISI Web of Science (1975 to date of search) (searched 19 March 2008); and National Research Register (online) (Issue 3 2007) (searched 03 September 2007); C2SPECTR (searched 09 April 2008). We also searched PubMed (25 March 2008) to retrieve "related articles" for 15 studies included in a previous version of this review.

\section{Selection criteria}

Randomised and quasi-randomised controlled trials of methods to increase recruitment to randomised controlled trials. This includes non-healthcare studies and studies recruiting to hypothetical trials. Studies aiming to increase response rates to questionnaires or trial retention, or which evaluated incentives and disincentives for clinicians to recruit patients were excluded. 


\section{Data collection and analysis}

Data were extracted on the method evaluated; country in which the study was carried out; nature of the population; nature of the study setting; nature of the study to be recruited into; randomisation or quasi-randomisation method; and numbers and proportions in each intervention group. We used risk ratios and their $95 \%$ confidence intervals to describe the effects in individual trials, and assessed heterogeneity of these ratios between trials.

\section{Main results}

We identified 27 eligible trials with more than 26,604 participants. There were 24 studies involving interventions aimed directly at trial participants, while three evaluated interventions aimed at people recruiting participants. All studies were in health care.

Some interventions were effective in increasing recruitment: telephone reminders to non-respondents (RR 2.66, 95\% CI 1.37 to 5.18), use of opt-out, rather than opt-in, procedures for contacting potential trial participants (RR 1.39, 95\% CI 1.06 to 1.84 ) and open designs where participants know which treatment they are receiving in the trial (RR 1.25, 95\% CI 1.18 to 1.34 ). However, some of these strategies have disadvantages, which may limit their widespread use. For example, opt-out procedures are controversial and open designs are by definition unblinded. The effects of many other recruitment strategies are unclear; examples include the use of video to provide trial information to potential participants and modifying the training of recruiters. Many studies looked at recruitment to hypothetical trials and it is unclear how applicable these results are to real trials.

\section{Authors' conclusions}

Trialists can increase recruitment to their trials by using the strategies shown to be effective in this review: telephone reminders; use of opt-out, rather than opt-in; procedures for contacting potential trial participants and open designs. Some strategies (e.g. open trial designs) need to be considered carefully before use because they also have disadvantages. For example, opt-out procedures are controversial and open designs are by definition unblinded.

\section{PLAIN LANGUAGE SUMMARY}

\section{Strategies to recruit participants to randomised trials}

Many trials do not recruit sufficient participants and this can make it more difficult to use the results of the research in practice. Effective strategies for improving recruitment would be of great benefit to researchers designing and running trials. This review did find some strategies that can increase recruitment to trials. Researchers could telephone non-respondents to remind them about the trial. The research team could use opt-out, rather than opt-in, procedures for contacting potential trial participants, or they could use an open design where participants know which treatment they are receiving in the trial, rather than having some of them receive a placebo or dummy intervention to mask this. However, some of these effective strategies have disadvantages, which may limit their widespread use. The effect of many other recruitment strategies is unclear. Many studies have looked at recruitment to mock trials and it is difficult to know how their findings would apply to real trials. It would be better if more researchers included an evaluation of recruitment strategies in real trials.

\section{B A C K G R O U N D}

Randomised controlled trials are the gold-standard for the evaluation of the effectiveness and safety of healthcare interventions, particularly because they protect against selection bias (Kunz 2007). However, recruiting clinicians and patients to randomised trials can be extremely difficult.

Poor recruitment can lead to an underpowered study, which may report clinically relevant effects to be statistically non-significant. In such cases, it is important to bear in mind that absence of evi- 
dence of a difference is not evidence of the absence of a difference (Altman 1995). A non-significant finding increases the risk that an effective intervention will be abandoned before its true value is established, or that there will be a delay in demonstrating this value while more trials or meta-analyses are done. Underpowered trials also raise an ethical problem: trialists have exposed participants to an intervention with uncertain benefit but may still be unable to determine whether the intervention does more good than harm on completion of the trial. Poor recruitment can also lead to the trial being extended, which increases cost.

Although investigations of recruitment differ in their estimates of the proportion of studies that achieve their recruitment targets, it is likely that less than $50 \%$ meet their target, or meet their target without extending the length of the trial (Charlson 1984; Haidich 2001; Foy 2003; McDonald 2006). For example, McDonald et al found that only $38(31 \%)$ of the 114 trials they studies achieved their original recruitment target and 65 (53\%) were extended ( McDonald 2006). The overall start to recruitment was delayed in $47(41 \%)$ trials and early recruitment problems were identified in $77(63 \%)$ trials. Foy et al studied seven primary care trials of dyspepsia management and only one achieved its recruitment target; five recruited less than $50 \%$ of their target and three of these closed prematurely because of recruitment problems (Foy 2003).

Trialists use many interventions to improve recruitment (see for example Prescott 1999 and Watson 2006) but it is generally difficult to predict the effect of these interventions. This Cochrane Methodology review is based on an earlier review by Mapstone et al (Mapstone 2007), for which the search had been last updated in April 2002. This updated review uses a revised search strategy, is focused on interventions to improve recruitment to randomised controlled trials (rather than to research studies in general) and aims, among other things, to consider the effect of study setting on recruitment.

\section{O B J E C T I VES}

The primary objective is to quantify the effects of strategies to improve recruitment of participants to randomised controlled trials. A secondary objective is to assess the evidence for the effect of the research setting (e.g. primary care versus secondary care) on recruitment.

\section{METHODS}

\section{Criteria for considering studies for this review}

\section{Types of studies}

Randomised and quasi-randomised controlled trials of interventions to improve recruitment of participants to randomised controlled trials.

\section{Types of data}

Randomised and quasi-randomised controlled trials of recruitment strategies set in the context of trials but not limited to healthcare; since interventions that work in other fields could be applicable to healthcare settings. Strategies both within real settings and in hypothetical trials (studies that ask potential participants whether they would take part in a trial if it was run, but the study does not actually run the trial) are eligible. Research into ways to improve questionnaire response and research looking at incentives and disincentives for clinicians to recruit patients to trials were excluded as these issues are addressed by complementary Cochrane Methodology reviews (Edwards 2009; Rendell 2007). Studies of retention strategies were excluded.

\section{Types of methods}

Any intervention that aimed to improve recruitment of participants to a randomised controlled trial. The interventions being studied could be directed at potential participants (e.g. patients being randomised to a trial), collaborators (e.g. clinicians recruiting patients for a trial), or others (e.g. research ethics committees). Examples of such interventions are letters introducing the trial being signed by eminent people, alternative methods of providing information about the trial to potential participants, additional training for collaborators, monetary incentives for participants, telephone follow up of expressions of interest and modifications to the design of the trial (e.g. using a preference design).

\section{Types of outcome measures}

\section{Primary outcomes}

- Proportion of eligible individuals or centres recruited.

- Proportion of patients with full follow-up.

\section{Secondary outcomes}

- Rate at which participants were recruited.

- Number and characteristics of the different types of people (participants, researchers, etc) who agree to take part. 


\section{Search methods for identification of studies}

We searched the following electronic databases without language restriction for eligible studies:

- The Cochrane Methodology Review Group Specialised Register (CMR), (The Cochrane Library (online) Issue 1 2008) (searched 20 February 2008)

- MEDLINE, Ovid (1950 to date of search) (searched on 06 May 2008)

- EMBASE, Ovid (1980 to date of search) (searched on 16 May 2008)

- ERIC, CSA (1966 to date of search) (searched 19 March 2008)

- Science Citation Index Expanded, ISI Web of Science (1975 to date of search) (searched 19 March 2008)

- Social Sciences Citation Index, ISI Web of Science (1975 to date of search) (searched 19 March 2008)

- National Research Register (online) (Issue 3 2007)

(searched 03 September 2007)

- C2-SPECTR (searched 09 April 2008)

- PubMed (searched 25 March 2008)

The UK Cochrane Centre developed and ran a series of search strategies in MEDLINE in 2000 to identify reports of methodological studies and records for such studies that were identified have been added to CMR. A series of search strategies for methodology studies had also been developed and run in EMBASE in 2004. Therefore, to increase the efficiency of our searches and to retrieve records not yet entered into CMR, our search of MEDLINE was limited to records entered from 2001 and, for EMBASE, we limited the search to records entered from 2005. The UK National Research Register was archived in September 2007 which is why it has not been searched more recently (see UK Clinical Trials Gateway portal.nihr.ac.uk/Pages/NRRArchive.aspx).

PubMed was searched to retrieve "related articles" for 15 studies included in the earlier version of this review by Mapstone et al (Mapstone 2007) (Aaronson 1996; Berner 1997; Cooper 1997; Funkhouser 2000; Kendrick 2001; Kiernan 20000; Koepsell 1996; Llewellyn-Thomas 1995a; Martinson 2000; Myles 1999; Rogers 1998; Simel 1991; Valanis 1998; Welton 1999; Weston 1997).

The full search strategies for all databases are included in Appendix 1.

\section{Data collection and analysis}

We have included the protocol for this updated review in Appendix 2 to make it available alongside this review in The Cochrane Library.

\section{Selection of studies}

Two reviewers independently screened the titles and abstracts of all references identified by the search strategy. The full versions of papers not definitely excluded at that stage were obtained for detailed review. All potentially eligible studies were independently assessed by two reviewers to determine if they met the inclusion criteria. Where differences of opinion occurred, these were discussed and, when necessary, full papers were read by a third reviewer.

\section{Data extraction and management}

Data extraction of each included article (using a proforma specifically designed for the purpose) was carried out independently by two reviewers (ST and EM). Differences in data extraction were resolved by discussion. Data were extracted on the method evaluated; country in which the study was carried out; nature of the population; nature of the study setting; nature of the study to be recruited into; randomisation or quasi-randomisation method; and numbers and proportions of participants in the intervention and comparator groups of the study comparing recruitment strategies.

\section{Assessment of risk of bias in included studies}

The adequacy of allocation concealment (adequate, unclear and inadequate) was assessed for each study (Schulz 1995). Other aspects of methodological quality, such as completeness of reporting of results and loss to follow-up were also considered. Data on methodological quality are presented in an additional table for all included studies. Completeness of reporting was assessed with reference to the ability to judge whether allocation was concealed (i.e. unclear for allocation concealment implies incomplete reporting) but also with regard to clear information on participants, intervention, comparator and outcome measure. Reporting of information on the flow of participants through the trial (e.g. from a CONSORT diagram) was recorded.

Results were interpreted in light of methodological quality but we did not exclude studies because of low quality. The risk of bias is summarised in line with the guidance in the Cochrane Handbook for Systematic Reviews of Interventions (v5.0.1), namely: A: Low risk of bias; B: Moderate risk of bias; C: High risk of bias. Concealment of allocation (adequate versus inadequate or unclear) was considered as a potential cause of heterogeneity in subgroup analysis, where there were sufficient studies.

\section{Analysis}

Trials have been grouped according to the type of intervention (e.g. monetary incentives, alternative forms of consent). Interventions have been grouped where they were similar in form and content. Binary data were combined as risk ratios (RR) with the associated 95\% confidence intervals. Cluster randomised trials were only included in the meta-analysis if sufficient data were reported to 
allow inclusion of analyses that adjusted for clustering. Pre-specificied subgroups (target group, setting, recruitment to real versus hypothetical trial) were assessed if sufficient studies were available.

\section{Assessment of heterogeneity}

Statistical evidence of heterogeneity of results of trials was sought using the chi-square test for heterogeneity and quantification of the degree of heterogeneity observed in the results was done using the I-squared statistic (Higgins 2003). Where substantial heterogeneity was detected, possible explanations were investigated informally, and the data summarised using a random-effects analysis if appropriate. We planned to explore the following factors in subgroup analyses, assuming enough studies were identified, as we believed that these were plausible explanations for heterogeneity:

- Type of design used to evaluate recruitment strategies (randomised versus quasi-randomised) and concealment of allocation (adequate versus inadequate or unclear)

- Setting of the study recruiting participants (e.g. primary versus secondary care; healthcare versus non-healthcare settings)

- Design of the study recruiting participants (e.g. open versus blinded studies, trials with placebo arms versus those without)

- Target group (e.g. ethics committees, clinicians, patients)

- Recruitment to hypothetical versus real trials

\section{Assessment of reporting biases}

Reporting (publication) bias was investigated for the primary outcomes using a funnel plot where ten or more studies were available.

\section{R E S U L T S}

\section{Description of studies}

See: Characteristics of included studies; Characteristics of excluded studies; Characteristics of studies awaiting classification.

See Characteristics of included studies; Characteristics of excluded studies.

9633 titles and abstracts were screened and the full text of 220 articles was needed to confirm inclusion, or address uncertainties among reviewers as to whether the article should be included, generally due to the lack of an abstract. We were able to obtain the full text of 186 of these articles. The remaining 34 articles were not obtained for this version of the review because (mostly) the title or abstract reference was incomplete or incorrect, or the article was not in English (three articles) and translation could not be arranged. Translation of these articles will be arranged for future updates of this review.
Of the 186 articles for which full text was obtained, 27 were eligible for inclusion. There were 24 studies involving interventions aimed directly at trial participants. Three studies evaluated interventions aimed at those recruiting participants. More than 26,604 individuals were involved in the 27 studies; but it was not clear how many participants were recruited in two studies, both of which involved interventions aimed at recruiters, rather than those being recruited. The figure of 26,604 includes both individuals who were recruited to randomised controlled trials, as well as those who were approached about recruitment but declined.

Nine categories of intervention were evaluated, all of which were used in connection with healthcare studies. There were too few studies evaluating the same or similar interventions to allow us to do any of our planned subgroup analyses.

One study (Ellis 2002) was identified as eligible late in the review process, and will be included in the next update of this review.

\section{Risk of bias in included studies}

See Characteristics of included studies.

All studies were described by their authors as either randomised (25 studies) or quasi-randomised (two studies). Allocation concealment was considered to have been present for 16 studies, not clear for nine and not met for two. The overall assessment of the risk of bias was considered as Low risk of bias for nine studies, Moderate risk of bias for eight studies and High risk of bias for ten studies.

\section{Effect of methods}

The recruitment interventions were placed into nine broad categories. One (modification to the consent form or processes) included six different variations on consent procedures and one (modification to the approach made to potential participants) included 15 variations on the way potential trial participants were approached about the trial (see Table 1). Although these two categories each contain several studies, we considered the interventions to be sufficiently different to make pooling them inappropriate. The lines between categories were not always clear, particularly that between changes to the trial design and modification to consent procedures.

We placed studies according to the emphasis given by the original authors of the study. For example, although Fowell 2006 involved a change to consent procedures, we placed it under 'Other change to trial design versus conventional design' because the authors' emphasis was on the use of cluster randomisation to increase recruitment. We accept that this is a judgement and welcome feedback on how we can improve our categorisation. Our nine categories are: 
- Open RCT versus blinded RCT

- Placebo versus other comparator

- Other change to trial design versus conventional RCT design

- Modification to the consent form or process

- Opt-out consent versus opt-in consent

- Consent to experimental care versus usual consent

- Consent to standard care versus usual consent

- Refusers choose treatment versus usual consent

- Physician modified consent versus usual consent

- Participant modified consent versus usual consent

- Modification to the approach made to potential participants

- Educational video versus standard information

- Educational video with written information versus written information

- Telephone screening versus face-to-face screening

- Enhanced recruitment package versus standard recruitment package

- Enhanced recruitment package with baseline data collected by telephone versus standard recruitment package

- Enhanced recruitment package with recruitment at churches versus standard recruitment package

- Clinical trial booklet with standard information versus standard information

- Home safety questionnaire with trial invitation versus trial invitation

- Positive framing of side effects versus neutral framing

- Negative framing of side effects versus neutral framing

- Interactive computer presentation of trial information versus audio-taped presentation

- Writing treatment effect is 'twice as fast' in trial information versus writing 'half as fast'

- Total information disclosure versus standard disclosure

- Electronic completion of screening questionnaire versus standard paper completion

- Oral completion of screening questionnaire versus standard paper completion

- Financial incentives for participants

- Telephone reminders

- Modification to the training given to recruiters

- Greater contact between trial coordinator and trial sites

\section{Open RCT versus blinded RCT}

Two studies (Avenell 2004 (fracture prevention trial); Hemminki 2004 (postmenopausal hormone therapy trial)) with 4833 participants compared an open design (participants know what treatment they are receiving) to a blinded, placebo-controlled design. An open design improved recruitment compared to a blinded design (RR 1.25, 95\% CI 1.18, 1.34) (Analysis 1.1).

\section{Placebo versus other comparator}

Welton 1999 (436 participants) investigated the effect of a placebo group on willingness of women to take part in a hypothetical hormone replacement trial and found that the number of women who would definitely or probably take part may be less with a placebo as comparator (RR 0.76, 95\% CI 0.59 to 0.99 ) (Analysis 2.1). It was not clear whether participants were told what the placebo would be (eg. a tablet that did not contain an active ingredient) and the applicability of this result to real trials is unclear.

\section{Other change to trial design versus conventional RCT design}

Two studies (326 participants) looked at other trial design changes. Cooper 1997 compared recruitment in a partially randomised patient preference design (participants with a strong preference for one treatment or another receive it, while the remainder are randomised) with a conventional randomised design for a trial of management strategies for heavy menstrual bleeding. Of the 135 women allocated to the preference arm, $40 \mathrm{had}$ a strong preference for a particular treatment, 90 were willing to be randomised and five refused. Those allocated to the preference design were more likely to agree to take part in the study as a whole (RR 1.37, 95\% CI 1.22 to 1.53 ) but this made little or no difference to recruitment to the randomised trial (RR $0.95,95 \% \mathrm{CI} 0.81$ to 1.11) (Analysis 3.1). Fowell 2006 compared cluster randomisation in a palliative care trial to individual consent after randomisation if the participant was randomised to the experimental treatment (sometimes called a Zelen design) in a cross-over trial. The study had only two sites (clusters) with few participants: 6 out of 24 potential participants were recruited in the cluster arm, compared to 0 out of 29 in the Zelen arm.

\section{Modification to the consent form or process}

Four studies (3182 participants) evaluated the effect of changes to the consent form or consent process. Two of the studies involved real trials. The other two were hypothetical trials. The effect of participants having to contact the trial team to take part in a trial (opt-in) compared to having to contact the trial team if they did not wish to be approached about the trial (opt-out) was studied by Trevena 2006 in a trial of decision aids for screening of colorectal cancer by faecal occult blood testing. Opt-out improved recruitment (RR 1.39, 95\% CI 1.06 to 1.84) (Analysis 4.1).

Two studies involving recruitment to hypothetical trials (Gallo 1995 (trial of a hypothetical new drug); Myles 1999 (anaesthesia trial)) evaluated various combinations of prerandomisation and consent (e.g. prerandomised consent to receive the experimental treatment). Two interventions were common between the two studies: a) seeking consent to receive the experimental treatment and b) seeking consent to receiving the standard treatment. Seeking consent to receive experimental treatment probably leads to 
little or no difference in recruitment (Analysis 5.1). Seeking consent to receive the standard treatment probably decreased recruitment (RR 0.67, 95\% CI 0.61 to 0.75 ) but there was considerable heterogeneity $\left(\mathrm{I}^{2}=93 \%\right)$ (Analysis 6.1).

There were three other comparisons in these two studies that were not common to both:

- usual consent compared to a consent process that allowed those refusing to be randomised to choose whether they wanted the experimental or standard treatment (Gallo 1995)

- usual consent compared to consenting to a 7 in 10 chance of getting the experimental treatment because the clinician believes experimental treatment is more effective (Myles 1999)

- usual consent compared to consenting to the participant selecting the chance $(6,7$ or 8 in 10$)$ of receiving the experimental treatment (Myles 1999)

All three interventions probably led to little or no difference in recruitment (Analysis 7.1, Analysis 8.1, Analysis 9.1).

Coyne 2003 ran a cluster trial involving 44 oncology centres to compare a consent form designed to be easy to read with the organisation's standard consent form. Although the authors did not present centre-level recruitment data, or provide an intracluster correlation coefficient, they did consider intracluster correlation in their analysis and found that recruitment did not differ significantly between the two trial groups $(\mathrm{P}=0.32)$.

\section{Modification to the approach made to potential participants}

Twelve studies involving trial participants (16,433 participants) and one involving the centres that recruit participants (126 centres) evaluated the effect of modifying trial information, or the way it was delivered. Seven of the studies involved real trials and six were hypothetical trials.

Three studies (Du 2008; Weston 1997; Fureman 1997) investigated the use of educational videos although the way they were used was different in each study. Du 2008 investigated the effect of an 18-minute educational video on recruitment to a range of therapeutic and non-therapeutic cancer trials, but the intervention probably led to little or no difference in recruitment (Analysis 10.1). Weston 1997 compared the effect on willingness to participate of a 10-minute video plus written information versus written information only in a trial evaluating management policies for pregnant women with prelabour rupture of membranes. The video probably improved willingness to participate (RR 1.75, 95\% CI 1.11 to 2.74 ) (Analysis 11.1).

Fureman 1997 used a 26-minute video as supplement to a pamphlet to try and improve willingness to take part in a hypothetical preventive HIV vaccine trial. The number of individuals willing to take part was not presented in the published paper but willingness as measured on a composite $0-4$ score was higher in the video group (1.69) than in the pamphlet-only group (1.50) up to two months after seeing the video, although this difference was not statistically significant.

Diguiseppi 2006 compared the effect on willingness to participate in a hypothetical future lifestyle change trial of telephone screening for hazardous drinking versus face-to-face administration in the clinic. Telephone screening may have improved willingness to take part compared to face-to-face administration (RR 1.26, 95\% CI 1.06 to 1.50) (Analysis 12.1). Ford 2004 developed three enhanced recruitment interventions to recruit African Americans to a cancer trial. The enhancements included using African Americans to conduct screening interviews, collecting baseline information by telephone rather than mailed questionnaire and faceto-face recruitment sessions at African American churches. These were compared to the standard recruitment procedure. The most intense intervention, which included the church sessions, probably led to an improvement in recruitment (RR 1.37, 95\% CI 1.05 to 1.78) (Analysis 15.1). The two other interventions probably led to little or no difference in recruitment (Analysis 13.1; Analysis 14.1). Graham 2007 compared the effect on willingness to take part in a hypothetical lifestyle change trial of electronic, oral and paper-and-pencil completion of a screening questionnaire. These interventions may not have led to any difference in recruitment (Analysis 16.1; Analysis 17.1).

Kendrick 2001 mailed a home safety questionnaire to families together with an invitation to participate in an injury prevention trial and found that recruitment was improved when compared to families receiving just the invitation (RR 1.37, 95\% CI 1.13 to 1.65 ) (Analysis 18.1). We identified three other interventions involved booklets:

- standard information compared to an HIV clinical trial information booklet plus standard trial information (Ives 2001)

- neutrally-framed information on side-effects in a colon cancer trial compared to negatively-framed information (Llewellyn-Thomas 1995a)

- neutrally-framed information on side-effects in a colon cancer trial compared to positively-framed information (Llewellyn-Thomas 1995a)

All three interventions probably led to little or no difference in recruitment (Analysis 19.1; Analysis 20.1; Analysis 21.1).

Llewellyn-Thomas $1995 \mathrm{~b}$ found that an interactive computer presentation of trial information probably slightly improved recruitment to a hypothetical cancer trial compared to an audio-tape presentation (RR 1.48, 95\% CI 1.00 to 2.18) (Analysis 22.1).

Simel 1991 used two different consent forms for a hypothetical trial of a new medication, one saying the new treatment may work 'twice as fast', the other saying the new treatment may work 'half as fast', as standard care. Both consent forms were read aloud to potential participants. The first consent form probably improved recruitment (RR $1.62,95 \%$ CI 1.10 to 2.37 ) although it is not clear how applicable this result is to real trials (Analysis 23.1). Simes 1986 compared provision of total disclosure of a range of information relevant to a cancer trial versus more limited default 
disclosure with additional provision being at the discretion of the clinician. The intervention led to little or no difference in recruitment (Analysis 24.1).

Kimmick 2005 ran a cluster trial involving 126 oncology centres to compare the effect of an educational intervention aimed at improving recruitment of older participants at cancer centres that were part of a network of cancer centres. Although the authors did not present centre-level recruitment data, or provide an intracluster correlation coefficient, they did consider intracluster correlation in their analysis. An educational package comprising standard information plus a symposium, additional educational materials, monthly mailings and emails for one year, lists of trial protocols to attach to patient charts and a seminar did not significantly increase recruitment compared to standard information alone (31\% of participants aged over 65 in both intervention and control groups in year $2, \mathrm{P}=0.83$ ).

\section{Financial incentives for participants}

One study with 270 participants (Bentley 2004) investigated the effect of three levels of risk presentation (high, medium and low) and three levels of financial incentive ( $\$ 1800, \$ 800$ and $\$ 350)$, giving nine interventions in total, on willingness to take part in a hypothetical trial. The number of individuals willing to participate is not given in the published report for the study but financial incentives increased willingness to participate for all three risk levels $(\mathrm{P}=0.015)$. For a fixed risk, willingness to participate increased with the size of the financial incentive for each of the three risk levels.

\section{Telephone reminders}

One study with 498 participants (Nystuen 2004) evaluated the effect of telephone reminders on recruitment to a trial investigating an intervention to support sick-listed individuals get back to work. Telephone reminders improved recruitment (RR 2.66, 95\% CI 1.37 to 5.18) (Analysis 25.1).

\section{Modification to the training given to recruiters}

One study with 96 recruiters (Larkey 2002) evaluated the effect of using trained Hispanic women already taking part in a trial as lay advocates to refer women to trials within the Women's Health Initiative. The training comprised six hours of training in informal sessions and concentrated on the communication of benefits to Latinas of being in the trial. The authors did not report an analysis that corrected for the clustering or provide an intracluster correlation coefficient. Data at the recruiter aggregate level were reported on whether a recruiter did or did not recruit anyone to the trial. Eight of the 28 trained Hispanic recruiters recruited one or more women to the trial whereas none of the 26 untrained Hispanic women recruited anyone the trial. Two of the 42 untrained Anglo control group recruited two women.

\section{Greater contact between trial coordinator and trial sites}

Two studies investigated the effect of greater contact between trial coordinators and trial sites in multicentre cluster trials. Liénard 2006 (135 trial sites) evaluated onsite initiation visits to review the trial protocol, inclusion and exclusion criteria, safety, randomisation and other trial aspects in a multicentre breast cancer trial. They did not provide sufficient data to allow for an analysis which adjusted for clustering. The authors did not present the proportion of eligible participants recruited, only the number recruited: visited sites recruited 302 participants while those not receiving visits recruited 271 . The difference was reported to be not statistically significant (no P-value was given). Monaghan 2007 (167 trial sites) evaluated the effect of additional communication strategies (e.g. individually-tailored feedback on recruitment) with trial sites. The authors did not present the proportion of eligible participants recruited. Site level analyses of the time to meet half of the site's recruitment target and the median number recruited were reported. The median total number of participants in the additional communication group was 37.5 , compared to 37.0 in the standard communication group. This difference was not statistically significant $(\mathrm{P}=0.68)$. Intervention centres achieved half their recruitment targets in 4.4 months, compared to 5.8 months for control centres. This difference was not statistically significant $(\mathrm{P}=$ $0.08)$.

\section{DISCUSSION}

This review identified 27 studies that evaluated the effect of nine categories of strategies to improve recruitment to randomised controlled trials. The interventions used in these studies varied significantly, which made it difficult to pool data. Even those studies based on the same basic strategy (e.g. changing the consent process) were generally sufficiently different to make pooling inappropriate (Engels 2000). For example, although there were four studies and six interventions looking at changes to consent procedures, only two interventions were similar enough to be pooled. Videos were used in three studies but delivered different information, or were used in combination with other interventions that differed between studies. We did not feel that it was appropriate to combine the findings of hypothetical and real trials.

Most studies did not provide clear evidence of benefit. Many studies were small, likely to be underpowered and with confidence intervals including the possibility of substantial benefit. This is particularly true of interventions that modified the approach made to potential participants by, for example, presenting trial information to them in different ways. Moreover, many studies involved hypothetical trials and it is not clear how applicable their results 
are to real trials. Our suggestion to trialists is to build evaluations of recruitment interventions into their real trials rather than use hypothetical trials. Additionally, we had hoped to be able to do a number of subgroup analyses but the variations in the interventions themselves would have made these comparisons meaningless. Other reasons for not doing the planned subgroup analyses were:

- Randomised versus quasi-randomised: only two quasirandomised studies, both studying hypothetical trials.

- Primary versus secondary care; healthcare versus nonhealthcare settings: small number of primary care studies and non-healthcare settings.

- Design of the study recruiting participants (e.g. open versus blinded studies, trials with placebo groups versus those without): not done as a subgroup analysis but the two example comparisons were part of the main analysis.

- Target group (e.g. ethics committees, clinicians, patients): too few studies aimed at participants other than patients.

Some interventions do appear to be effective. Telephone reminders to non-responders (Nystuen 2004), opt-out procedures requiring potential participants to contact the trial team if they did not want to be contacted about a trial (Trevena 2006), making the trial open rather than blinded (Avenell 2004; Hemminki 2004) and mailing a questionnaire about home safety to potential participants to an injury prevention trial (Kendrick 2001) all improved recruitment in high quality studies involving real trials. While it is not clear if the latter intervention has wider applicability, the first two interventions could in principle be used in many trials. This is especially true of telephone reminders. Opt-out has been proposed by others (e.g. Hewison 2006) as a way of improving recruitment to health research but it remains controversial because ethics committees generally require that research participants give their active, optin approval to research participation, including being contacted about the research by researchers. While it may be easier to recruit to an open trial, there is clearly a greater risk of bias with such trials over blinded trials.

The effect of other strategies to improve recruitment to trials remains less clear. Partial preference designs may improve recruitment to a study as a whole but not to the randomised part (Cooper 1997). Other than the opt-out strategy mentioned above, a whole range of strategies involving changes to consent procedures failed to produce promising recruitment strategies. Modifications to the way or quantity of information presented to potential participants about trials in general, or about one trial in particular, did not provide clear evidence in favour of this approach to improving recruitment. The one study involving financial incentives (Bentley
2004) found that increasing payment led to increased recruitment but this was to a hypothetical trial. Three studies looked at strategies aimed not at potential participants but at those recruiting them (Larkey 2002; Liénard 2006; Monaghan 2007) and none presented clear evidence in favour of the strategies used.

Potential bias was a problem in many of the included studies. Although allocation concealment was considered high quality for 16 of the 27 studies (it was unclear for nine and poor for two), the overall assessment of the risk of bias was considered as low for only nine studies. Ten studies were considered to be at high risk of bias. This was often linked to hypothetical trials. It was not possible to predict the direction of effect that any bias may have had on study outcomes. We were unable to make judgements about the likelihood of publication bias with our relatively small number of included studies and the wide variation in the recruitment strategies being evaluated.

A number of potentially eligible studies identified by our search were not included in this review because we were unable to arrange translation (three studies), because the reference returned by the search was incomplete or incorrect (24 studies), or we were unable to get the full text before submission of this review (seven). We will aim to obtain sufficient information to include or exclude these studies when we update this review. We would welcome feedback about studies that we have missed.

\section{AUTHORS' CONCLUSIONS}

\section{Implication for systematic reviews and evaluations of healthcare}

Trialists can increase recruitment to their trials by using the strategies shown to be effective in this review: telephone reminders to non-respondents; use of opt-out, rather than opt-in procedures for contacting potential trial participants; and open designs. The use of open trial designs needs to be considered carefully since the lack of blinding may lead to bias. Evidence is inconclusive for several interventions, including the use of video to provide information to potential participants, some types of change to consent procedures and financial incentives. There is evidence to suggest that preference designs, the use of a placebo as a comparator, and greater contact between trial coordinators and recruiting sites may not increase recruitment.

\section{Implication for methodological research}

Trialists should include evaluations of their recruitment strategies in their trials and funders should support this because the number of interventions that have been rigorously evaluated in the context 
of a real trial is low. The use of hypothetical trials to study recruitment strategies has its place but it would be better if methodologists could collaborate with trialists to study recruitment in real trials. There is a clear gap in knowledge with regard to effective strategies aimed at recruiters and research into how to increase recruitment by sites participating in trials would be beneficial.

\section{ACKNOW LEDGEMENTS}

We would like to thank Hatim Osman for his help with screening abstracts and Marian Pandal for her help to obtain full text articles.

\section{RE F E R E N E S}

\section{References to studies included in this review}

Avenell 2004 \{published data only\}

Avenell A, Grant AM, McGee M, McPherson G, Campbell MK, McGee MA (for the RECORD Trial Management Group). The effects of an open design on trial participant recruitment, compliance and retention - a randomized controlled trial comparison with a blinded, placebocontrolled design. Clinical Trials 2004;1:490-498.

Bentley 2004 \{published data only\}

Bentley JP, Thacker PG. The influences of risk and monetary payment on the research participation decision making process. Journal of Medical Ethics 2004;30:293-298.

Cooper 1997 \{published data only\}

Cooper KG, Grant AM, Garratt AM. The impact of using a partially randomised patient preference design when evaluating alternative managements for heavy menstrual bleeding. Journal of Obstetrics and Gynaecology 1997;104: 1367-1373.

Coyne 2003 \{published data only\}

Coyne CA, Xu R, Raich P, Plomer K, Dignan M, Wenzel LB, Fairclough D, Habermann T, Schell L, Quella S, Cella D. Randomized, controlled trial of an easy-to-read informed consent statement for clinical trial participation: a study of the Eastern Cooperative Oncology Group. Journal of Clinical Oncology 2003;21(5):836-842.

Diguiseppi 2006 \{published data only\} Diguiseppi C, Goss C, Xu S, Magid D, Graham A. Telephone screening for hazardous drinking among injured patients seen in acute care clinics: feasibility study. Alcohol \& Alcoholism 2006;41(4):438-445.

Du 2008 \{published data only\}

Du W, Mood D, Gadgeel S, Simon MS. An educational video to increase clinical trials enrolment among lung cancer patients. Journal of Thoracic Oncology 2008;3(1):23-29.

Ford 2004 \{published data only\}

Ford ME, Havstad SL, Davis SD. A randomized trial of recruitment methods for older African American men in the
Prostate, Lung, Colorectal and Ovarian (PLCO) cancer screening trial. Clinical Trials 2004;1:343-351.

Fowell 2006 \{published data only\}

Fowell A, Johnstone R, Finlay IG, Russell D, Russell IT. Design of trials with dying patients: a feasibility study of cluster randomisation versus randomised consent. Palliative Medicine 2006;20:799-804.

Fureman 1997 \{published data only\} Fureman I, Meyers K, McLellan AT, Metzger D, Woody G. Evaluation of a video-supplement to informed consent: injection drug users and preventive HIV vaccine efficacy trials. AIDS Education and Prevention 1997;9(4):330-341.

Gallo 1995 \{published data only\}

Gallo C, Perrone F, De Placido S, Giusti C. Informed versus randomised consent to clinical trials. The Lancet 1995;346: $1060-1064$.

Graham 2007 \{published data only\}

Graham A, Goss C, Xu S, Magid D, Diguiseppi C. Effect of using different modes to administer the AUDIT-C on identification of hazardous drinking and acquiescence to trial participation among injured patients. Alcohol \& Alcoholism 2007;42(5):423-429.

Hemminki 2004 \{published data only\} Hemminki E, Hovi SL, Veerus P, Sevon T, Tuimala R, Rahu M, Hakama M. Blinding decreased recruitment in a prevention trial of postmenopausal hormone therapy. Journal of Clinical Epidemiology 2004;57:1237-1243.

Ives 2001 \{published data only\} Ives NJ, Troop M, Waters A, Davies S, Higgs C, Easterbrook PJ. Does an HIV clinical trial information booklet improve patient knowledge and understanding of HIV clinical trials? . HIV Medicine 2001;2:241-249.

Kendrick 2001 \{published data only\} Kendrick D, Watson M, Dewey M, Woods AJ. Does sending a home safety questionnaire increase recruitment to an injury prevention trial? A randomised controlled trial. Journal of Epidemiology and Community Health 2001;55: 845-846. 
Kimmick 2005 \{published data only\}

Kimmick GG, Peterson BL, Kornblith AB, Mandelblatt J, Johnson JL, Wheeler J, Heinze R, Cohen HJ, Muss HB. Improving accrual of older persons to cancer treatment trials: a randomized trial comparing an educational intervention with standard information: CALGB 360001. Journal of Clinical Oncology 2005;23(10):2201-2207.

Larkey 2002 \{published data only\}

Larkey LK, Staten LK, Ritenbaugh C, Hall RA, Buller DB, Bassford T, Rempfer Altimari B. Recruitment of Hispanic women to the Women?s Health Initiative: the case of Embajadoras in Arizona. Controlled Clinical Trials 2002;23: 289-298.

Liénard 2006 \{published data only\}

Liénard J-L, Quinax E, Fabre-Guillevin E, Piedbois P, Jouhaud A, Decoster G, Buyse M. Impact of on-site initiation visits on patient recruitment and data quality in a randomized trial of adjuvant chemotherapy for breast cancer. Clinical Trials 2006;3:486-492.

Llewellyn-Thomas 1995a \{published data only\} Llewellyn-Thomas HA, McGreal MJ, Thiel EC. Cancer patients decision making and trial-entry preferences: the effects of framing information about short-term toxicity and long-term survival. Medical Decision Making 1995;15: 4-12.

Llewellyn-Thomas 1995b \{published data only\} Llewellyn-Thomas HA, Thiel EC, Sem FWC, Woermke DEH. Presenting clinical trial information: a comparison of methods. Patient Education and Counseling 1995;25: 97-107.

Monaghan 2007 \{published data only\} Monaghan H, Richens A, Colman S, Currie R, Girgis S, Jayne K, Neal B, Patel A. A randomised trial of the effects of an additional communication strategy on recruitment into a large-scale, multi-centre trial. Contemporary Clinical Trials 2007;28:1-5.

Myles 1999 \{published data only\}

Myles PS, Fletcher HE, Cairo S, Madder H, McRae R, Cooper J, Devonshire D, Hunt JO, Richardson J, Machlin H, Morgan EB, Moloney J, Downey G. Randomized trial of informed consent and recruitment for clinical trials in the immediate preoperative period. Anesthesiology 1999;91: 969-978.

Nystuen 2004 \{published data only\}

Nystuen P, Hagen KB. Telephone reminders are effective in recruiting nonresponding patients to randomized controlled trials. Journal of Clinical Epidemiology 2004;57:773-776.

Simel 1991 \{published data only\}

Simel DL, Feussner JR. A randomized controlled trial comparing quantitative informed consent formats. Journal of Clinical Epidemiology 1991;44(8):771-777.

Simes 1986 \{published data only\}

Simes RJ, Tattersall MHN, Coates AS, Raghavan D,

Solomon HJ. Randomised comparison of procedures for obtaining informed consent in clinical trials of treatment for cancer. British Medical Journal 1986;293:1065-1068.
Trevena 2006 \{published data only\}

Trevena L, Irwig L, Barratt A. Impact of privacy legislation on the number and characteristics of people who are recruited for research: a randomised controlled trial. Journal of Medical Ethics 2006;32:473-477.

Welton 1999 \{published data only\}

Welton AJ, Vickers MR, Cooper JA, Meade TW, Marteau

TM. Is recruitment more difficult with a placebo arm in randomised controlled trials? A quasi randomised, interview based study. British Medical Journal 1991;318: 1114-1117.

Weston 1997 \{published data only\} Weston J, Hannah M, Downes J. Evaluating the benefits of a patient information video during the informed consent process. Patient Education and Counseling 1997;30: 239-245.

\section{References to studies excluded from this review}

Aaronson 1996 \{published data only\}

Aaronson NK, Visser-Pol E, Gerleen HMW, et al.TelephoneBased Nursing Intervention Improves the Effectiveness of the Informed Consent Process in Cancer Clinical Trials. Journal of Clinical Oncology 1996;14:984-996.

Junghans 2005 \{published data only\} Junghans C, Feder G, Hemingway H, Timmis A, Jones $M$. Recruitingpatients to medical research: double blind randomised trial of "opt-in" versus "opt-out" strategies. BMJ 2005;331:940.

Kiernan 2000 \{published data only\} Kiernan M, Phillips K, Fair J, King AC. Using direct mail to recruit Hispanic adults into a dietary intervention: an experimental study. Annals of Behavioral Medicine 2000;22 (1):89-93.

Lancet 2001 \{published data only\}

Unknown. Recruitment of women to clinical trials. Lancet 2001;358:853.

Rogers 1998 \{published data only\} Rogers CG, Tyson JE, Kennedy KA, Broyles RS, Hickman JF. Conventional consent with opting in versus simplified consent with opting out: an exploratory trial for studies that do not increase patient risk. Journal of Pediatrics 1998;132: 606-611.

Saul 2002 \{published data only\}

Saul H. Influences on recruitment in clinical trials. European Journal of Cancer 2002;38:2334.

Wragg 2000 \{published data only\}

Wragg JA, Robinson EJ, Lilford RJ. Information presentation and decisions to enter clinical trials: a hypothetical trial of hormone replacement therapy. Social Science and Medicine 2000;51:453-462.

\section{References to studies awaiting assessment}

\section{Caldwell $2002\{$ published data only\}}

Caldwell P, Craig J, Hamilton S. [Strategies for recruitment to RCTs: a systematic review of controlled trials and 
observational studies]. International Clinical Trials Symposium: improving health care in the new millenium. October 21-23; Sydney, Australia, 34-35. 2002.

Calimlim 1977 \{published data only\}

Calimlim J, Wardell WM, Lasagna L. Selection, attrition, and consent in recruitment of patients for a clinical trial. Clinical Pharmacology \& Therapeutics 1977;21:100.

Cramer 1993 \{published data only\}

Cramer JA. Patient recruitment and compliance issues in clinical trials. Epilepsy Research. Supplement 1993;10: 211-222.

Dal-Re 1991 \{published data only\}

Dal-Ré R. Clinical trial of drugs: a study of the influence of information on adverse reactions on obtaining of informed consent. Medicina Clinica 1991;96:566-569.

Glen 1980 \{published data only\}

Glen VH. Patient involvement utilizing video cassettes. Ontario Dentist 1980;57:20-21.

Gomez 1998 \{published data only\}

Gómez Arnáu JI. Preoperative information and informed consent from surgical patients. Revista Espanola de Anestesiologia y Reanimacion 1998;45(9):401.

Greenlee 2003 \{published data only\}

Greenlee H, Gonzalez AJ, Lampe JW. Recruitment feasibility for a pilot randomized controlled trial on the effect of naturopathic therapies on estrogen metabolism. Cancer Epidemiology Biomarkers \& Prevention 2003;12: 1302s.

Lichter 1991 \{published data only\}

Lichter PR. Patient recruitment for clinical trials. Ophthalmology 1991;98:1489-1490.

Monane 1991 \{published data only\}

Monane $\mathrm{M}$, et al.The randomized controlled trial in the long-term care setting - recruitment and enrollment. Journal of the American Geriatrics Society 1991;39:A51.

Perrone 1995 \{published data only\} Perrone F, De Placido S, Giusti C, Gallo C. The request for consent in clinical research: a randomized study in healthy subjects. Epidemiologia e Prevenzione 1995;19:282-290.

Unknown \{published data only\}

\section{Additional references}

Altman 1995

Altman DG, Bland JM. Absence of evidence is not evidence of absence. British Medical Journal 1995;311:485.

Berner 1997

Berner ES, Partridge EE, Baum SK. The effects of the PDQ

patient information fi le (PIF) on patients' knowledge, enrollment in clinical trials, and satisfaction. Journal of cancer education: the official journal of the American Association for Cancer Education 1997;12:121-125.

Charlson 1984

Charlson ME, Horwitz RI. Applying results of randomised trials to clinical practice: impact of losses before randomisation. British Medical Journal 1984;289:

1281-1284.

Edwards 2009

Edwards PJ, Roberts I, Clarke MJ, DiGuiseppi C, Wentz R, Kwan I, Cooper R, Felix LM, Pratap S. Methods to increase response rates to postal questionnaires. Cochrane Database of Systematic Reviews 2009, Issue 3. [DOI: 10.1002/ 14651858.MR000008.pub4]

Ellis 2002

Ellis PM, Butow PN, Tattersall MH. Informing breast cancer patients about clinical trials: a randomized clinical trial of an educational booklet. Annals of Oncology 2002;13: $1414-1423$.

Engels 2000

Engels EA, Schmid CH, Terrin N, Oilkin I, Lau J.

Heterogeneity and statistical signifi cance in meta-analyses: an empirical study of 125 meta-analyses. Statistics in Medicine 2000;19:1707-1728.

Foy 2003

Foy R, Parry J, Duggan A, Delaney B, Wilson S, Lewinvan den Broek NTh, Lassen A, Vickers L, Myres P. How evidence-based are recruitment strategies for randomized controlled trials in primary care? Experience from seven studies. Family Practice 2003;20:83-92.

Funkhouser 2000

Funkhouser E, Macaluso M, Wang X. Alternative strategies for selecting population controls: comparison of random digit dialing and targeted telephone calls. Annals of Epidemiology 2000;10:59-67.

\section{Haidich 2001}

Haidich AB, Ioannidis JPA. Patterns of patient enrolment in randomized controlled trials. Journal of Clinical Epidemiology 2001;54:877-883.

Hewison 2006

Hewison J, Haines A. Overcoming barriers to recruitment in health research. BMJ 2006;333:300-302.

Higgins 2003

Higgins JPT, Thompson SG, Deeks JJ, Altman DG. Measuring inconsistency in metaanalyses. British Medical Journal 2003;327:557-560.

\section{Koepsell 1996}

Koepsell TD, McGuire V, Longstreth WT, Nelson LM, van Belle G. Randomized trial of leaving messages on telephone answering machines for control recruitment in an epidemiologic study. American Journal of Epidemiology 1996;144:704-706.

\section{Kunz 2007}

Kunz R, Vist G, Oxman AD. Randomisation to protect against selection bias in healthcare trials. Cochrane Database of Systematic Reviews 2007, Issue 2. [DOI: 10.1002/ 14651858.MR000012.pub2]

\section{Mapstone 2007}

Mapstone J, Elbourne D, Roberts I. Strategies to improve recruitment to research studies. Cochrane Database 
of Systematic Reviews 2007, Issue 2. [DOI: 10.1002/ 14651858.MR000013.pub3]

\section{Martinson 2000}

Martinson BC, Lazovich D, Lando HA, Perry CL, McGovern PG, Boyle RG. Effectiveness of monetary incentives for recruiting adolescents to an intervention trial to reduce smoking. Preventive medicine 2000;31:706-713.

\section{McDonald 2006}

McDonald AM, Knight RC, Campbell MK, Entwistle VA, Grant AM, Cook JA, Elbourne DR, Francis D, Garcia J, Roberts I, Snowdon C. What influences recruitment to randomised controlled trials? A review of trials funded by two UK funding agencies. Trials 2006;7:9.

\section{Prescott 1999}

Prescott RJ, Counsell CE, Gillespie WJ, Grant AM, Russell IT, Kiauka $S$, et al.Factors that limit the quality,number and progress of randomised controlled trials. Health Technology Assessment 1999;3(20):1-143.

\section{Rendell 2007}

Rendell JM, Merritt RK, Geddes JR. Incentives and disincentives to participation by clinicians in randomised controlled trials. Cochrane Database of
Systematic Reviews 2007, Issue 2. [DOI: 10.1002/ 14651858.MR000021.pub3]

\section{Rogers 1998}

Rogers CG, Tyson JE, Kennedy KA, Broyles RS, Hickman JF. Conventional consent with opting in versus simplified consent with opting out: an exploratory trial for studies that do not increase patient risk. Journal of Pediatrics 1998;132: 606-611.

\section{Schulz 1995}

Schulz KF, Chalmers I, Hayes RJ, Altman DG. Dimensions of methodological quality associated with estimates of treatment effects in controlled trials. Journal of the American Medical Association 1995;273(5):408-412.

\section{Valanis 1998}

Valanis B, Blank J, Glass A. Mailing strategies and costs of recruiting heavy smokers in CARET, a large chemoprevention trial. Controlled clinical trials 1998;19: 25-38.

Watson 2006

Watson JM, Torgerson DJ. Increasing recruitment to randomised trials: a review of randomised controlled trials. BMC Medical Research Methodology 2006;6:34.

* Indicates the major publication for the study 


\section{CHARACTERISTICS OF STUDIES}

\section{Characteristics of included studies [ordered by study ID]}

\section{Avenell 2004}

\begin{tabular}{|c|c|c|}
\hline Methods & \multicolumn{2}{|c|}{ Randomised controlled trial. } \\
\hline Data & \multicolumn{2}{|c|}{$\begin{array}{l}\text { Setting: secondary care, UK. Participants were patients aged } 70 \text { or over attending a fracture clinic or } \\
\text { orthopaedic ward. } 538 \text { participants }\end{array}$} \\
\hline Comparisons & \multicolumn{2}{|c|}{$\begin{array}{l}\text { Investigated the effect of different trial designs. } \\
\text { Open trial design comparing vitamin } \mathrm{D} \text {, versus calcium, versus vitamin } \mathrm{D} \text { and calcium, versus no tablets. } \\
\text { Compared to conventional trial comparing vitamin } \mathrm{D} \text {, versus calcium, versus vitamin } \mathrm{D} \text { and calcium, } \\
\text { versus placebo }\end{array}$} \\
\hline Outcomes & \multicolumn{2}{|c|}{ Proportion recruited to trial. } \\
\hline Notes & \multicolumn{2}{|c|}{ Overall risk of bias - A: Low risk of bias. } \\
\hline \multicolumn{3}{|l|}{ Risk of bias } \\
\hline Item & Authors' judgement & Description \\
\hline Allocation concealment? & Yes & \\
\hline Blinding? & Yes & $\begin{array}{l}\text { Blinding only partial but looking at the effect of open study design was } \\
\text { the purpose of the study }\end{array}$ \\
\hline Objective outcomes? & Yes & \\
\hline
\end{tabular}

Bentley 2004

\begin{tabular}{|c|c|}
\hline Methods & Randomised controlled trial. \\
\hline Data & Setting: university, USA. Participants were pharmacy students. 270 participants \\
\hline Comparisons & $\begin{array}{l}\text { Investigated the effect of financial incentives and trial risk } \\
\text { Nine-arm trial looking at the effect of financial incentives and bonus based on the level of risk (high, } \\
\text { medium or low) associated with the intervention drug } \\
\text { Interventions A-C: information on high-risk trial for a drug not yet tested on humans, paying one of } \\
\$ 1800, \$ 800 \text { or } \$ 350 \\
\text { Interventions D-F: information on medium-risk study for a generic drug already on the market, paying } \\
\text { one of } \$ 1800, \$ 800 \text { or } \$ 350 \\
\text { Intervention G-I: information on low-risk study measuring salivary levels of stress hormones, paying one } \\
\text { of } \$ 1800, \$ 800 \text { or } \$ 350\end{array}$ \\
\hline Outcomes & ingness to take part in hypothetical studies. \\
\hline
\end{tabular}


Bentley 2004 (Continued)

\begin{tabular}{|c|c|c|}
\hline Notes & \multicolumn{2}{|c|}{ Overall risk of bias - C: High risk of bias. } \\
\hline \multicolumn{3}{|l|}{ Risk of bias } \\
\hline Item & Authors' judgement & Description \\
\hline Allocation concealment? & Yes & \\
\hline Blinding? & No & \\
\hline Objective outcomes? & No & Hypothetical trial. \\
\hline
\end{tabular}

\section{Cooper 1997}

\begin{tabular}{|c|c|c|}
\hline Methods & \multicolumn{2}{|c|}{ Randomised controlled trial. } \\
\hline Data & \multicolumn{2}{|c|}{ Setting: secondary care, UK. First time attendees at a gynaecological clinic. 273 participants } \\
\hline Comparisons & \multicolumn{2}{|c|}{$\begin{array}{l}\text { Investigated the effect of different trial designs. } \\
\text { Partially randomised patient preference design allocating to medical management or transcervical resection } \\
\text { of the endometrium or preferred option. Comparator was a conventional trial design allocating to medical } \\
\text { management or transcervical resection of the endometrium }\end{array}$} \\
\hline Outcomes & \multicolumn{2}{|c|}{ Proportion recruited to trial. } \\
\hline Notes & \multicolumn{2}{|c|}{ Overall risk of bias - A: Low risk of bias. } \\
\hline \multicolumn{3}{|l|}{ Risk of bias } \\
\hline Item & Authors' judgement & Description \\
\hline Allocation concealment? & Yes & \\
\hline Blinding? & Yes & Participants were blinded but not investigators. \\
\hline Objective outcomes? & Yes & \\
\hline
\end{tabular}

\section{Coyne 2003}

\begin{tabular}{ll}
\hline Methods & Randomised controlled trial. \\
\hline Data & Setting: secondary care, USA. Patients eligible for participation in a cancer treatment trial. 226 participants \\
\hline Comparisons & $\begin{array}{l}\text { Investigated the effect of different consent methods. } \\
\text { Easy to read consent statements (altered text style, layout, font size, vocabulary; reading level 7-8th grade) } \\
\text { were compared to standard consent statements }\end{array}$
\end{tabular}


Coyne 2003 (Continued)

\begin{tabular}{|c|c|c|}
\hline Outcomes & \multicolumn{2}{|c|}{ Proportion recruited to trial. } \\
\hline Notes & \multicolumn{2}{|c|}{ Overall risk of bias - C: High risk of bias. } \\
\hline \multicolumn{3}{|l|}{ Risk of bias } \\
\hline Item & Authors' judgement & Description \\
\hline Blinding? & Unclear & $\begin{array}{l}\text { Nurse clearly knew that the participant had intervention or control consent } \\
\text { statement; not clear how much participant was told about the intervention. } \\
\text { Not clear if telephone interviewers knew the allocation }\end{array}$ \\
\hline Objective outcomes? & Yes & \\
\hline
\end{tabular}

\section{Diguiseppi 2006}

\begin{tabular}{|c|c|c|}
\hline Methods & \multicolumn{2}{|c|}{ Quasi-randomised controlled trial. } \\
\hline Data & \multicolumn{2}{|c|}{$\begin{array}{l}\text { Setting: health maintenance organisation, USA. Participants were patients aged } 18 \text { or over attending the } \\
\text { HMO with an acute injury. } 469 \text { participants }\end{array}$} \\
\hline Comparisons & \multicolumn{2}{|c|}{$\begin{array}{l}\text { Investigated the effect of different methods of pre-screening participants } \\
\text { Telephone administered questionnaire on hazardous drinking and willingness to participate in lifestyle } \\
\text { intervention. This was compared to face-to-face administered questionnaire on hazardous drinking and } \\
\text { willingness to participate in lifestyle intervention }\end{array}$} \\
\hline Outcomes & \multicolumn{2}{|c|}{ Proportion recruited to hypothetical trial. } \\
\hline Notes & \multicolumn{2}{|c|}{ Overall risk of bias - C: High risk of bias. } \\
\hline \multicolumn{3}{|l|}{ Risk of bias } \\
\hline Item & Authors' judgement & Description \\
\hline Allocation concealment? & No & By week. \\
\hline Blinding? & Unclear & $\begin{array}{l}\text { Potential participants were probably blind but researchers and prac- } \\
\text { tice staff were not blind }\end{array}$ \\
\hline Objective outcomes? & No & Hypothetical trial. \\
\hline
\end{tabular}




\begin{tabular}{|c|c|c|}
\hline Methods & \multicolumn{2}{|c|}{ Randomised controlled trial. } \\
\hline Data & \multicolumn{2}{|c|}{$\begin{array}{l}\text { Setting: secondary care, USA. Patients aged } 21-80 \text { attending multidisciplinary lung clinic at a cancer centre. } \\
126 \text { participants }\end{array}$} \\
\hline Comparisons & \multicolumn{2}{|c|}{$\begin{array}{l}\text { Investigated the effect of different methods of providing information about the trial } \\
\text { 18-minute educational video giving an overview of clinical trials and the importance of cancer clinical research } \\
\text { to society. This was compared to standard care (i.e. normal first visit to oncologist) }\end{array}$} \\
\hline Outcomes & \multicolumn{2}{|c|}{ Proportion recruited to trial. } \\
\hline Notes & \multicolumn{2}{|c|}{ Overall risk of bias - B: Moderate risk of bias. } \\
\hline \multicolumn{3}{|l|}{ Risk of bias } \\
\hline Item & Authors' judgement & Description \\
\hline Blinding? & Yes & $\begin{array}{l}\text { Oncologist was blinded but the participant was not (not clear if they were } \\
\text { told that intervention was a video versus standard care) }\end{array}$ \\
\hline Objective outcomes? & Yes & \\
\hline
\end{tabular}

\section{Ford 2004}

\begin{tabular}{|c|c|}
\hline Methods & Randomised controlled trial. \\
\hline Data & $\begin{array}{l}\text { Setting: community, USA. African American men aged } 55-74 \text { eligible for a prostate, lung and colorectal } \\
\text { cancer screening trial. } 12,400 \text { participants }\end{array}$ \\
\hline Comparisons & $\begin{array}{l}\text { Investigated the effect of different trial information and consent methods } \\
\text { Intervention A: Enhanced recruitment letter, telephone call by African American interviewer, baseline infor- } \\
\text { mation by mail, reminder calls / mailings for baseline information / consent } \\
\text { Intervention B: Enhanced recruitment letter, telephone call by African American interviewer, baseline infor- } \\
\text { mation over telephone, reminder calls / mailings for consent form } \\
\text { Intervention C: Enhanced recruitment letter, telephone call by African American interviewer, church session, } \\
\text { baseline information at church session } \\
\text { Compared to standard recruitment letter, telephone assessment by African American or Caucasian interviewer, } \\
\text { baseline information by mail, reminder calls / mailings for baseline information / consent }\end{array}$ \\
\hline Outcomes & Proportion recruited to trial. \\
\hline Notes & Overall risk of bias - B: Moderate risk of bias. \\
\hline \multicolumn{2}{|l|}{ Risk of bias } \\
\hline Item & Authors' judgement \\
\hline
\end{tabular}


Ford 2004 (Continued)

\begin{tabular}{|c|c|c|}
\hline Blinding? & Unclear & $\begin{array}{l}\text { Potential participants were blinded but the researchers probably were not } \\
\text { blinded }\end{array}$ \\
\hline Objective outcomes? & Yes & \\
\hline
\end{tabular}

\section{Fowell 2006}

\begin{tabular}{ll}
\hline Methods & Randomised controlled trial. \\
\hline Data & $\begin{array}{l}\text { Setting: secondary care, UK. Cancer inpatients receiving palliative care and starting on a syringe driver. 53 } \\
\text { participants }\end{array}$ \\
\hline Comparisons & $\begin{array}{l}\text { Investigated the effect of different trial designs. } \\
\text { Cluster randomisation compared to Zelen's design (in which only those randomised to the intervention group } \\
\text { were asked for consent) }\end{array}$ \\
\hline Outcomes & Proportion recruited to trial. \\
\hline Notes & Overall risk of bias - C: High risk of bias. \\
\hline
\end{tabular}

\section{Risk of bias}

\begin{tabular}{lll}
\hline Item & Authors' judgement & Description \\
\hline Blinding? & Yes & $\begin{array}{l}\text { Blinding only partial but looking at the effect of open study design was the } \\
\text { purpose of the study }\end{array}$ \\
\hline Objective outcomes? & Yes & \\
\hline
\end{tabular}

Fureman 1997

\begin{tabular}{ll}
\hline Methods & Randomised controlled trial. \\
\hline Data & Setting: university, USA. Participants in the Risk Assessment Project (injection drug users). 188 participants \\
\hline Comparisons & $\begin{array}{l}\text { Investigated the effect of different trial information methods } \\
\text { Enhanced video on an HIV vaccine trial plus } 1 \text { hour pamphlet presentation (5 minutes pre-test, } 26 \text { minutes } \\
\text { of video, } 10 \text { minutes to review pamphlet, research assistant initiated question and answer session, post-test } \\
\text { questionnaire, survey at } 1 \text { month. This was compared to standard half hour pamphlet-only presentation }(5 \\
\text { minutes pre-test, } 10 \text { minutes to review trial information pamphlet, research assistant initiated question and } \\
\text { answer session, post-test questionnaire, survey at } 1 \text { month }\end{array}$ \\
\hline Outcomes & \begin{tabular}{l} 
Willingness to take part in hypothetical trial (expressed as a score on a willingness scale) \\
\hline Notes
\end{tabular} \\
\hline
\end{tabular}

\section{Risk of bias}

Strategies to improve recruitment to randomised controlled trials (Review) 
Fureman 1997

\begin{tabular}{|c|c|c|}
\hline Item & Authors' judgement & Description \\
\hline Blinding? & Unclear & $\begin{array}{l}\text { Not clear how much participants were told before the study, not clear what the } \\
\text { research assistant running sessions knew about randomisation; probably knew } \\
\text { that video was the intervention. Assistant could in principle influence post- } \\
\text { test questionnaire responses of participants because these were done during } \\
\text { the session }\end{array}$ \\
\hline Objective outcomes? & No & Hypothetical trial. \\
\hline
\end{tabular}

\section{Gallo 1995}

\begin{tabular}{|c|c|c|}
\hline Methods & \multicolumn{2}{|c|}{ Randomised controlled trial. } \\
\hline Data & \multicolumn{2}{|c|}{$\begin{array}{l}\text { Setting: community, Italy. Members of the general public aged under } 80 \text { years, attending a scientific exhibition. } \\
2035 \text { participants }\end{array}$} \\
\hline Comparisons & \multicolumn{2}{|c|}{$\begin{array}{l}\text { Investigated the effect of different consent methods. } \\
\text { Intervention A: if person consents to participate, standard or new treatment assigned at random; if no consent, } \\
\text { can choose standard or new treatment } \\
\text { Intervention B: randomised consent to standard treatment; if no consent given new treatment. } \\
\text { Intervention C: randomised consent to new treatment; if no consent given standard treatment. } \\
\text { Standard consent procedure (treatment group allocated at random) }\end{array}$} \\
\hline Outcomes & \multicolumn{2}{|c|}{ Willingness to take part in hypothetical trial. } \\
\hline Notes & \multicolumn{2}{|c|}{ Overall risk of bias - C: High risk of bias. } \\
\hline \multicolumn{3}{|l|}{ Risk of bias } \\
\hline Item & Authors' judgement & Description \\
\hline Blinding? & Unclear & $\begin{array}{l}\text { Not clear what participants were told. Researchers unblinded and since the } \\
\text { researcher asked participants for their views at the end of test, there is the } \\
\text { potential for bias }\end{array}$ \\
\hline Objective outcomes? & No & Hypothetical trial. \\
\hline
\end{tabular}




\begin{tabular}{l|l}
\hline Methods & Quasi-randomised controlled trial. \\
\hline Data & $\begin{array}{l}\text { Setting: health maintenance organisation, USA. Participants were patients aged } 18 \text { or over attending the } \\
\text { HMO with an acute injury. } 370 \text { participants }\end{array}$ \\
\hline Comparisons & $\begin{array}{l}\text { Investigated the effect of different methods of pre-screening participants } \\
\text { Intervention A: Electronic questionnaire on hazardous drinking and willingness to participate in lifestyle } \\
\text { intervention. }\end{array}$ \\
\hline $\begin{array}{l}\text { Intervention B: Oral questionnaire read aloud to patients in the clinic, potential answers printed on cards } \\
\text { and patients asked to point. }\end{array}$ \\
\hline Compared to standard self-complete paper questionnaire. \\
\hline Outcomes & Willingness to take part in a hypothetical trial. \\
\hline Notes & Overall risk of bias - C: High risk of bias. \\
\hline
\end{tabular}

\section{Risk of bias}

\begin{tabular}{l|l|l}
\hline Item & Authors' judgement & Description \\
\hline Allocation concealment? & No & By week. \\
\hline Blinding? & Yes & $\begin{array}{l}\text { Potential participants probably blind but not researchers or practice } \\
\text { staff }\end{array}$ \\
\hline Objective outcomes? & No & Hypothetical trial. \\
\hline
\end{tabular}

Hemminki 2004

\begin{tabular}{|c|c|c|}
\hline Methods & \multicolumn{2}{|c|}{ Randomised controlled trial. } \\
\hline Data & \multicolumn{2}{|c|}{ Setting: 'local clinics', Estonia. Postmenopausal women aged 50-64 } \\
\hline Comparisons & \multicolumn{2}{|c|}{$\begin{array}{l}\text { Investigated the effect of different design methods. } \\
\text { Non-blinded allocation comparing active HRT treatment versus no treatment. This was compared to } \\
\text { traditional blinded allocation comparing active HRT treatment versus placebo }\end{array}$} \\
\hline Outcomes & \multicolumn{2}{|c|}{ Proportion recruited to trial. } \\
\hline Notes & \multicolumn{2}{|c|}{ Overall risk of bias - A: Low risk of bias. } \\
\hline \multicolumn{3}{|l|}{ Risk of bias } \\
\hline Item & Authors' judgement & Description \\
\hline Allocation concealment? & Yes & \\
\hline
\end{tabular}


Hemminki 2004 (Continued)

\begin{tabular}{l|l|l}
\hline Blinding? & Yes & $\begin{array}{l}\text { Blinding only partial but looking at the effect of open study design was } \\
\text { the purpose of the study }\end{array}$ \\
\hline Objective outcomes? & Yes & \\
\hline
\end{tabular}

Ives 2001

\begin{tabular}{l|l}
\hline Methods & Randomised controlled trial. \\
\hline Data & Setting: secondary care, UK. Patients attending an HIV hospital clinic. 50 participants \\
\hline Comparisons & $\begin{array}{l}\text { Investigated the effect of different trial information methods } \\
\text { Standard trial information plus booklet entitled, "Clinical Trials in HIV and AIDS: Information for people } \\
\text { who are thinking about joining a trial". This was compared to standard trial information (information } \\
\text { sheet specific to proposed trial, plus discussion with trial doctor and research nurse) }\end{array}$ \\
\hline Outcomes & Proportion recruited to trial. \\
\hline Notes & Overall risk of bias - C: High risk of bias. \\
\hline Risk of bias & Authors' judgement \\
\hline Item & Yes \\
\hline Allocation concealment? & No \\
\hline Blinding? & Yes \\
\hline Objective outcomes? & Descrion \\
\hline
\end{tabular}

Kendrick 2001

\begin{tabular}{l|l}
\hline Methods & Randomised controlled trial. \\
\hline Data & $\begin{array}{l}\text { Setting: primary care, UK. Families with children aged under } 5 \text { years, living in deprived areas. 2393 } \\
\text { participants }\end{array}$ \\
\hline Comparisons & $\begin{array}{l}\text { Investigated the effect of different trial information methods } \\
\text { Mailed invitation to participate in an injury prevention trial, including a home safety questionnaire. This } \\
\text { was compared to mailed invitation to participate excluding the home safety questionnaire }\end{array}$ \\
\hline Outcomes & Proportion recruited to trial. \\
\hline Notes & Overall risk of bias - A: Low risk of bias. \\
\hline
\end{tabular}

\section{Risk of bias}


Kendrick 2001 (Continued)

\begin{tabular}{|c|c|c|}
\hline Item & Authors' judgement & Description \\
\hline Allocation concealment? & Yes & \\
\hline Blinding? & Yes & \\
\hline Objective outcomes? & Yes & \\
\hline
\end{tabular}

Kimmick 2005

\begin{tabular}{ll}
\hline Methods & Randomised controlled trial. \\
\hline Data & $\begin{array}{l}\text { Setting: secondary care and academic institutions. Practitioners and researchers from Cancer and Leukaemia } \\
\text { Group B (CALGB) institutions. } 126 \text { centres }\end{array}$ \\
\hline Comparisons & $\begin{array}{l}\text { Investigated the effect of different trial information methods } \\
\text { Educational intervention of standard information plus an educational symposium, geriatric oncology educa- } \\
\text { tional materials, monthly mailings and e-mails for 1 year, lists of available protocols for use on patient charts, } \\
\text { case discussion seminar. This was compared to standard information of periodic notification of all existing } \\
\text { CALGB trials by the CALGB Central Office, and CALGB web site access }\end{array}$ \\
\hline Outcomes & Proportion recruited to trial. \\
\hline Notes & Overall risk of bias - C: High risk of bias \\
\hline
\end{tabular}

\section{Risk of bias}

\begin{tabular}{|c|c|c|}
\hline Item & Authors' judgement & Description \\
\hline Blinding? & Unclear & $\begin{array}{l}\text { Not clear what details were given to the participants was about the study } \\
\text { before it started }\end{array}$ \\
\hline Objective outcomes? & Yes & \\
\hline
\end{tabular}

\section{Larkey 2002}

\begin{tabular}{l|l}
\hline Methods & Randomised controlled trial. \\
\hline Data & Setting: various existing trial sites, USA. Participants in the Womens Health Initiative trial. 53 participants \\
\hline Comparisons & $\begin{array}{l}\text { Investigated the effect of different methods of training lay advocates for trials } \\
\text { Intervention A: Hispanic lay advocates; attended six hour-long training sessions, five quarterly meetings, and } \\
\text { received brochures with interest cards to distribute to other women. }\end{array}$ \\
$\begin{array}{l}\text { Intervention B: Hispanic women controls, received quarterly telephone calls, and brochures with interest } \\
\text { cards to distribute to other women. }\end{array}$
\end{tabular}


Larkey 2002 (Continued)

Compared to Anglo women controls, received quarterly telephone calls, and brochures with interest cards to distribute to other women

\begin{tabular}{ll}
\hline Outcomes & Proportion recruited to trial. \\
\hline Notes & Overall risk of bias - B: Moderate risk of bias. \\
\hline
\end{tabular}

\section{Risk of bias}

\begin{tabular}{lll}
\hline Item & Authors' judgement & Description \\
\hline Blinding? & Unclear & Not clear if the participants were blinded. \\
\hline Objective outcomes? & Yes & \\
\hline
\end{tabular}

Liénard 2006

\begin{tabular}{|c|c|c|}
\hline Methods & \multicolumn{2}{|c|}{ Randomised controlled trial. } \\
\hline Data & \multicolumn{2}{|c|}{$\begin{array}{l}\text { Setting: secondary care, France. Centres recruiting to a randomised controlled trial for breast cancer. } 573 \\
\text { participants }\end{array}$} \\
\hline Comparisons & \multicolumn{2}{|c|}{$\begin{array}{l}\text { Investigated the effect of organising visits by the trial coordination team to centres participating in a } \\
\text { multicentre trial } \\
\text { Site visits including an initiation visit to review trial protocol, inclusion/exclusion criteria, safety, ran- } \\
\text { domisation etc. plus ongoing review visits. This was compared to no site visits (unless requested) }\end{array}$} \\
\hline Outcomes & \multicolumn{2}{|l|}{ Number recruited. } \\
\hline Notes & \multicolumn{2}{|c|}{ Overall risk of bias - A: Low risk of bias. } \\
\hline \multicolumn{3}{|l|}{ Risk of bias } \\
\hline Item & Authors' judgement & Description \\
\hline Allocation concealment? & Yes & \\
\hline Blinding? & Yes & \\
\hline Objective outcomes? & Yes & \\
\hline
\end{tabular}


Llewellyn-Thomas 1995a

\begin{tabular}{|c|c|c|}
\hline Methods & \multicolumn{2}{|c|}{ Randomised controlled trial. } \\
\hline Data & \multicolumn{2}{|c|}{$\begin{array}{l}\text { Setting: secondary care, Canada. Colorectal cancer patients attending cancer hospital as outpatients. } 90 \\
\text { participants }\end{array}$} \\
\hline Comparisons & \multicolumn{2}{|c|}{$\begin{array}{l}\text { Investigated the effect of different trial information methods } \\
\text { Intervention A: Booklet with negatively framed intervention about treatment side-effects and survival. } \\
\text { Intervention B: Booklet with positively framed intervention about treatment side-effects and survival. } \\
\text { Compared to booklet with neutrally framed intervention about treatment side-effects and survival }\end{array}$} \\
\hline Outcomes & \multicolumn{2}{|c|}{ Proportion recruited to hypothetical trial. } \\
\hline Notes & \multicolumn{2}{|c|}{ Overall risk of bias - B: Moderate risk of bias. } \\
\hline \multicolumn{3}{|l|}{ Risk of bias } \\
\hline Item & Authors' judgement & Description \\
\hline Allocation concealment? & Yes & \\
\hline Blinding? & Yes & Interviewer was blinded, but unclear about participants. \\
\hline Objective outcomes? & No & Hypothetical trial. \\
\hline
\end{tabular}

\section{Llewellyn-Thomas 1995b}

\begin{tabular}{l|l}
\hline Methods & Randomised controlled trial. \\
\hline Data & $\begin{array}{l}\text { Setting: secondary care, Canada. Patients attending the outpatient department of a cancer hospital. } 100 \\
\text { participants }\end{array}$ \\
\hline Comparisons & $\begin{array}{l}\text { Investigated the effect of different trial information methods } \\
\text { Searchable computerised information on a hypothetical trial, including purpose, description of treatment } \\
\text { group and randomisation, possible benefits, side-effects, and patients' rights. This was compared to tape- } \\
\text { recorded information on a hypothetical trial, including purpose, description of treatment arm and ran- } \\
\text { domisation, possible benefits, side-effects, and patients' rights }\end{array}$ \\
\hline Outcomes & Proportion recruited to hypothetical trial. \\
\hline Notes & Overall risk of bias - B: Moderate risk of bias. \\
\hline
\end{tabular}

\section{Risk of bias}

\begin{tabular}{lll}
\hline Item & Authors' judgement & Description \\
\hline
\end{tabular}

Allocation concealment? Yes 


\section{Llewellyn-Thomas 1995b (Continued)}

\begin{tabular}{|c|c|c|}
\hline Blinding? & Unclear & $\begin{array}{l}\text { Unclear if the interviewer or the participants were blinded. It depends on } \\
\text { what the participants were told. Interviewer did not seem to do more than } \\
\text { help with equipment, so perhaps limited room for bias }\end{array}$ \\
\hline Objective outcomes? & No & Hypothetical trial. \\
\hline
\end{tabular}

Monaghan 2007

\begin{tabular}{|c|c|c|}
\hline Methods & \multicolumn{2}{|c|}{ Randomised controlled trial. } \\
\hline Data & \multicolumn{2}{|c|}{$\begin{array}{l}\text { Setting: existing, multicentre, international trial. Clinical sites in } 19 \text { countries recruiting to a diabetes and } \\
\text { vascular disease treatment trial. } 167 \text { centres }\end{array}$} \\
\hline Comparisons & \multicolumn{2}{|c|}{$\begin{array}{l}\text { Investigated the effect of different levels of communication between the trial coordination team and } \\
\text { participating sites } \\
\text { Additional communication - usual plus frequent emails, regular personalised mail-outs of league tables/ } \\
\text { graphs of performance against other sites, certificates of achievement for recruitment/other study items } \\
\text { (one per month). This was compared to usual communication (provided via the regional centre) plus } \\
\text { occasional direct communications from the co-ordinating centre in the form of generic newsletters, emails } \\
\text { and faxes }\end{array}$} \\
\hline Outcomes & \multicolumn{2}{|c|}{ Proportion recruited to trial. } \\
\hline Notes & \multicolumn{2}{|c|}{ Overall risk of bias - A: Low risk of bias. } \\
\hline \multicolumn{3}{|l|}{ Risk of bias } \\
\hline Item & Authors' judgement & Description \\
\hline Allocation concealment? & Yes & \\
\hline Blinding? & Yes & Centres were blinded, but the central office was not blind. \\
\hline Objective outcomes? & Yes & \\
\hline
\end{tabular}

Myles 1999

\begin{tabular}{l|l}
\hline Methods & Randomised controlled trial. \\
\hline Data & $\begin{array}{l}\text { Setting: secondary care, Australia. Inpatients aged } 18 \text { or over, scheduled for elective surgery. } 769 \text { partici- } \\
\text { pants }\end{array}$ \\
\hline Comparisons & $\begin{array}{l}\text { Investigated the effect of different consent methods. } \\
\text { Intervention A: Pre-randomised to experimental drug and asked to provide consent; if no consent, standard } \\
\text { treatment given. }\end{array}$ \\
& Intervention B: Pre-randomised to standard drug and asked to provide consent; if no consent, experimental
\end{tabular}


treatment given.

Intervention C: Told that the physician thinks experimental drug superior, if consent given, has $70 \%$ chance of receiving this; if no consent, standard treatment given.

Intervention D: Allowed to increase or decrease their chance of receiving the experimental drug if consent given, and if no preference, $50 \%$ chance of receiving it; if no consent, standard treatment given.

Compared to standard randomisation method (equal chance of experimental or standard drug)

\begin{tabular}{|c|c|c|}
\hline Outcomes & \multicolumn{2}{|c|}{ Proportion recruited to hypothetical trial. } \\
\hline Notes & \multicolumn{2}{|c|}{ Overall risk of bias - B: Moderate risk of bias. } \\
\hline \multicolumn{3}{|l|}{ Risk of bias } \\
\hline Item & Authors' judgement & Description \\
\hline Allocation concealment? & Yes & \\
\hline Blinding? & Yes & $\begin{array}{l}\text { Patient is blinded (they are not told the exact details of the study in the } \\
\text { patient information). Researchers (probably) knew the allocation }\end{array}$ \\
\hline Objective outcomes? & No & Hypothetical trial. \\
\hline
\end{tabular}

Nystuen 2004

\begin{tabular}{l|l}
\hline Methods & Randomised controlled trial. \\
\hline Data & $\begin{array}{l}\text { Setting: community, Norway. Sick-listed employees attending a participating social security office. } 498 \\
\text { participants }\end{array}$ \\
\hline Comparisons & $\begin{array}{l}\text { Investigated the effect of different telephone reminders. } \\
\text { Written invitation to participate in a community-based trial followed by a telephone reminder if no re- } \\
\text { sponse within two weeks; guide used for discussion. This was compared to written invitation to participate } \\
\text { in a community-based trial followed by no reminder if no response within two weeks }\end{array}$ \\
\hline Outcomes & Proportion recruited to trial. \\
\hline Notes & Overall risk of bias - A: Low risk of bias. \\
\hline
\end{tabular}

\section{Risk of bias}

\begin{tabular}{|c|c|c|}
\hline Item & Authors' judgement & Description \\
\hline
\end{tabular}

Allocation concealment? Yes 
Nystuen 2004 (Continued)

\begin{tabular}{|c|c|c|}
\hline Blinding? & Yes & $\begin{array}{l}\text { Participants were blinded but not the research team, although the team } \\
\text { do not contact the control group }\end{array}$ \\
\hline Objective outcomes? & Yes & \\
\hline
\end{tabular}

Simel 1991

\begin{tabular}{ll}
\hline Methods & Randomised controlled trial. \\
\hline Data & Setting: secondary care, USA. Patients attending an ambulatory care clinic. 100 participants \\
\hline Comparisons & $\begin{array}{l}\text { Investigated the effect of different consent methods. } \\
\text { Consent form including a statement that the new treatment may work twice as fast as usual treatment. } \\
\text { This was compared to a consent form including a statement that the new treatment may work half as fast } \\
\text { as usual treatment }\end{array}$ \\
\hline Outcomes & Number consenting (inferred from data rather than being an outcome presented by authors) \\
\hline Notes & Overall risk of bias - B: Moderate risk of bias. \\
\hline
\end{tabular}

\section{Risk of bias}

\begin{tabular}{l|l|l}
\hline Item & Authors' judgement & Description \\
\hline Allocation concealment? & Yes & $\begin{array}{l}\text { Participants probably were blind but the investigators were not. Investi- } \\
\text { gators got an independent reviewer to look at a portion of interviews and } \\
\text { he/she thought they were fair. They also used a script so less room for } \\
\text { investigator initiative }\end{array}$ \\
\hline Blinding? & Unclear & Number consenting not presented as an outcome but inferred from data \\
\hline Objective outcomes? & No & Nom
\end{tabular}

Simes 1986

\begin{tabular}{l|l}
\hline Methods & Randomised controlled trial. \\
\hline Data & Setting: secondary care, Australia. Patients attending an oncology unit. 57 participants \\
\hline Comparisons & $\begin{array}{l}\text { Investigated the effect of different consent methods. } \\
\text { Individual approach to consent - patients given information about aims, expected results, potential toxi- } \\
\text { cities of treatment; details of treatment left to discretion of consultant; patients given opportunity to ask } \\
\text { questions, verbal consent obtained. This was compared to total disclosure approach - patients were fully } \\
\text { informed about all trial aspects by consultant: patients given opportunity to ask questions, also given a } \\
\text { consent form outlining the information; this was kept overnight and written consent was obtained the } \\
\text { following day }\end{array}$ \\
\hline
\end{tabular}




\section{Simes 1986 (Continued)}

\begin{tabular}{|c|c|c|}
\hline Outcomes & \multicolumn{2}{|c|}{ Proportion recruited to trial. } \\
\hline Notes & \multicolumn{2}{|c|}{ Overall risk of bias - A: Low risk of bias. } \\
\hline \multicolumn{3}{|l|}{ Risk of bias } \\
\hline Item & Authors' judgement & Description \\
\hline Allocation concealment? & Yes & \\
\hline Blinding? & Unclear & $\begin{array}{l}\text { Participants were probably blinded. Clinicians were probably not blinded. } \\
\text { It is not clear if it is the same clinicians provided information in to both } \\
\text { groups }\end{array}$ \\
\hline Objective outcomes? & Yes & \\
\hline
\end{tabular}

Trevena 2006

\begin{tabular}{|c|c|c|}
\hline Methods & \multicolumn{2}{|c|}{ Randomised controlled trial. } \\
\hline Data & \multicolumn{2}{|c|}{$\begin{array}{l}\text { Setting: primary care, Australia. Patients aged 50-74 eligible for a colorectal cancer screening trial. } 152 \\
\text { participants }\end{array}$} \\
\hline Comparisons & \multicolumn{2}{|c|}{$\begin{array}{l}\text { Investigated the effect of different trial information methods } \\
\text { Opt-in recruitment; letter from doctor advising that the practice is taking part in screening trial; would } \\
\text { only be contacted if contact details returned. This was compared to opt-out recruitment; letter from } \\
\text { doctor advising that the practice is taking part in screening trial; would be contacted unless the practice } \\
\text { was advised to withhold contact details }\end{array}$} \\
\hline Outcomes & \multicolumn{2}{|c|}{ Proportion recruited to trial. } \\
\hline Notes & \multicolumn{2}{|c|}{ Overall risk of bias - A: Low risk of bias. } \\
\hline \multicolumn{3}{|l|}{ Risk of bias } \\
\hline Item & Authors' judgement & Description \\
\hline Allocation concealment? & Yes & \\
\hline Blinding? & Yes & \\
\hline Objective outcomes? & Yes & \\
\hline
\end{tabular}


Welton 1999

\begin{tabular}{|c|c|c|}
\hline Methods & \multicolumn{2}{|c|}{ Quasi-randomised controlled trial. } \\
\hline Data & \multicolumn{2}{|c|}{ Setting: primary care, UK. Women aged 45-64 who had not had a hysterectomy. 436 participants } \\
\hline Comparisons & \multicolumn{2}{|c|}{$\begin{array}{l}\text { Investigated the effect of different trial information methods } \\
\text { Verbal information about a trial of HRT, comparing oestrogen only versus combined oestrogen and } \\
\text { progestogen. This was compared to verbal information about a trial of HRT, comparing oestrogen only, } \\
\text { versus combined oestrogen and progestogen, versus placebo }\end{array}$} \\
\hline Outcomes & \multicolumn{2}{|c|}{ Proportion recruited to hypothetical trial. } \\
\hline Notes & \multicolumn{2}{|c|}{ Overall risk of bias - C: High risk of bias. } \\
\hline \multicolumn{3}{|l|}{ Risk of bias } \\
\hline Item & Authors' judgement & Description \\
\hline Allocation concealment? & No & By week. \\
\hline Blinding? & Yes & Participants were blinded but the nurses were not. \\
\hline Objective outcomes? & No & Hypothetical trial. \\
\hline
\end{tabular}

Weston 1997

\begin{tabular}{|c|c|c|}
\hline Methods & \multicolumn{2}{|c|}{ Randomised controlled trial. } \\
\hline Data & \multicolumn{2}{|c|}{ Setting: secondary care, Canada. Women attending for antenatal visits. 90 participants } \\
\hline Comparisons & \multicolumn{2}{|c|}{$\begin{array}{l}\text { Investigated the effect of different trial information methods } \\
\text { Written study information followed by viewing of Term Prelabour Rupture of the Membranes (Term } \\
\text { PROM) video. This was compared to written study information only }\end{array}$} \\
\hline Outcomes & \multicolumn{2}{|c|}{ Proportion recruited to hypothetical trial. } \\
\hline Notes & \multicolumn{2}{|c|}{ Overall risk of bias - B: Moderate risk of bias } \\
\hline \multicolumn{3}{|l|}{ Risk of bias } \\
\hline Item & Authors' judgement & Description \\
\hline Allocation concealment? & Yes & \\
\hline Blinding? & Unclear & $\begin{array}{l}\text { Depends if the women were told they might watch a video - they probably } \\
\text { were told. Women completed a questionnaire so they were probably not } \\
\text { influenced by the study nurse }\end{array}$ \\
\hline
\end{tabular}


Weston 1997 (Continued)

Objective outcomes? No Hypothetical trial.

Characteristics of excluded studies [ordered by study ID]

\begin{tabular}{ll}
\hline Study & Reason for exclusion \\
\hline Aaronson 1996 & Not studying a recruitment intervention. \\
\hline Junghans 2005 & Not recruiting to a trial but to an observational study of patients with angina \\
\hline Kiernan 2000 & Studying response to an advertisment not actual recruitment. \\
\hline Lancet 2001 & Editorial. \\
\hline Rogers 1998 & Studying recall, understanding and satisfaction rather than effect on recruitment \\
\hline Saul 2002 & News item. \\
\hline Wragg 2000 & Allocation not randomised. \\
\hline
\end{tabular}

The above excluded studies and their reasons are provided as illustrative examples. A more complete list of excluded studies will be added in an update of this review. The majority of the studies that we considered in detail but excluded arose from articles that we ordered because the database reference gave no abstract and it was not possible to exclude on the basis of the title. The majority of articles falling into this category were excluded as soon as the full-text was checked, with the most common reason being that the study did not evaluate a recruitment intervention.

The two exceptions are Aaronson 1996 and Kiernan 2000, which were excluded at the data extraction stage for the reasons given in the table.

\section{Characteristics of studies awaiting assessment [ordered by study ID]}

\section{Caldwell 2002}

Methods

Data

Comparisons

Outcomes

Notes $\quad$ Full text to be obtained. 
Calimlim 1977

Methods

Data

Comparisons

Outcomes

Notes Full text to be obtained.

Cramer 1993

Methods

Data

Comparisons

Outcomes

Notes Full text to be obtained.

Dal-Re 1991

Methods

Data

Comparisons

Outcomes

Notes Awaiting translation.

Glen 1980

Methods

Data

Comparisons

Outcomes

Notes Full text to be obtained. 
Gomez 1998

Methods

Data

Comparisons

Outcomes

Notes Awaiting translation.

Greenlee 2003

Methods

Data

Comparisons

Outcomes

Notes Full text to be obtained.

Lichter 1991

Methods

Data

Comparisons

Outcomes

Notes Full text to be obtained.

Monane 1991

Methods

Data

Comparisons

Outcomes

Notes $\quad$ Full text to be obtained.


Methods

Data

Comparisons

\section{Outcomes}

Notes Awaiting translation.

Unknown

Methods

Data

Comparisons

Outcomes

Notes Incomplete or incorrect reference. 24 articles identified by our searches fell into this category, often because the database containing the reference only gave the article title, or did not give the journal name. We will attempt to identify these articles for consieration in an update to this review 
DATA ANDANALYSES

Comparison 1. Open RCT vs Blinded RCT

\begin{tabular}{lccccc} 
Outcome or subgroup title & $\begin{array}{c}\text { No. of } \\
\text { studies }\end{array}$ & $\begin{array}{c}\text { No. of } \\
\text { participants }\end{array}$ & Statistical method & Effect size \\
\hline 1 Participant recruited & 2 & 4833 & Risk Ratio (M-H, Fixed, 95\% CI) & $1.25[1.18,1.34]$ \\
\hline
\end{tabular}

Comparison 2. Placebo vs other comparator RCT

\begin{tabular}{lccccc} 
Outcome or subgroup title & $\begin{array}{c}\text { No. of } \\
\text { studies }\end{array}$ & $\begin{array}{c}\text { No. of } \\
\text { participants }\end{array}$ & Statistical method & Effect size \\
\hline 1 Participant recruited & 1 & 436 & Risk Ratio (M-H, Fixed, 95\% CI) & $0.76[0.59,0.99]$ \\
\hline
\end{tabular}

Comparison 3. Other change to trial design vs conventional RCT

\begin{tabular}{lcccc} 
Outcome or subgroup title & $\begin{array}{c}\text { No. of } \\
\text { studies }\end{array}$ & $\begin{array}{c}\text { No. of } \\
\text { participants }\end{array}$ & Statistical method & Effect size \\
\hline 1 Participant recruited & 1 & 273 & Risk Ratio (M-H, Fixed, 95\% CI) & $0.95[0.81,1.11]$ \\
\hline
\end{tabular}

Comparison 4. Opt-out consent vs opt-in consent

\begin{tabular}{lcccc} 
Outcome or subgroup title & $\begin{array}{c}\text { No. of } \\
\text { studies }\end{array}$ & $\begin{array}{c}\text { No. of } \\
\text { participants }\end{array}$ & Statistical method & Effect size \\
\hline 1 Participant recruited & 1 & 152 & Risk Ratio (M-H, Fixed, 95\% CI) & $1.39[1.06,1.84]$ \\
\hline
\end{tabular}




\begin{tabular}{lcccc} 
Outcome or subgroup title & $\begin{array}{c}\text { No. of } \\
\text { studies }\end{array}$ & $\begin{array}{c}\text { No. of } \\
\text { participants }\end{array}$ & Statistical method & Effect size \\
\hline 1 Participant recruited & 2 & 1672 & Risk Ratio (M-H, Fixed, 95\% CI) & $1.04[0.99,1.09]$ \\
\hline
\end{tabular}

Comparison 6. Consent to standard care vs usual consent

\begin{tabular}{lcccc} 
Outcome or subgroup title & $\begin{array}{c}\text { No. of } \\
\text { studies }\end{array}$ & $\begin{array}{c}\text { No. of } \\
\text { participants }\end{array}$ & Statistical method & Effect size \\
\hline 1 Participant recruited & 2 & 1229 & Risk Ratio (M-H, Fixed, 95\% CI) & $0.67[0.61,0.75]$ \\
\hline
\end{tabular}

Comparison 7. Refusers choose treatment vs usual consent

\begin{tabular}{lcccc} 
Outcome or subgroup title & $\begin{array}{c}\text { No. of } \\
\text { studies }\end{array}$ & $\begin{array}{c}\text { No. of } \\
\text { participants }\end{array}$ & Statistical method & Effect size \\
\hline 1 Participant recruited & 1 & 998 & Risk Ratio (M-H, Fixed, 95\% CI) & $0.96[0.90,1.02]$ \\
\hline
\end{tabular}

Comparison 8. Physician modified consent vs usual consent

\begin{tabular}{lcccc} 
Outcome or subgroup title & $\begin{array}{c}\text { No. of } \\
\text { studies }\end{array}$ & $\begin{array}{c}\text { No. of } \\
\text { participants }\end{array}$ & Statistical method & Effect size \\
\hline 1 Participant recruited & 1 & 301 & Risk Ratio (M-H, Fixed, 95\% CI) & $1.09[0.90,1.32]$ \\
\hline
\end{tabular}

Comparison 9. Participant modified consent vs usual consent

\begin{tabular}{lccccc} 
Outcome or subgroup title & $\begin{array}{c}\text { No. of } \\
\text { studies }\end{array}$ & $\begin{array}{c}\text { No. of } \\
\text { participants }\end{array}$ & Statistical method & Effect size \\
\hline 1 Participant recruited & 1 & 301 & Risk Ratio (M-H, Fixed, 95\% CI) & $1.02[0.83,1.24]$ \\
\hline
\end{tabular}


Comparison 10. Educational video vs standard information

\begin{tabular}{lcccc} 
Outcome or subgroup title & $\begin{array}{c}\text { No. of } \\
\text { studies }\end{array}$ & $\begin{array}{c}\text { No. of } \\
\text { participants }\end{array}$ & Statistical method & Effect size \\
\hline 1 Participant recruited & 1 & 126 & Risk Ratio (M-H, Fixed, 95\% CI) & $1.6[0.79,3.25]$ \\
\hline
\end{tabular}

Comparison 11. Educational video + written information vs written information

\begin{tabular}{lccccc} 
Outcome or subgroup title & $\begin{array}{c}\text { No. of } \\
\text { studies }\end{array}$ & $\begin{array}{c}\text { No. of } \\
\text { participants }\end{array}$ & Statistical method & Effect size \\
\hline 1 Participant recruited & 1 & 90 & Risk Ratio (M-H, Fixed, 95\% CI) & $1.75[1.11,2.74]$ \\
\hline
\end{tabular}

Comparison 12. Telephone screening vs face-to-face screening

\begin{tabular}{lcccc} 
Outcome or subgroup title & $\begin{array}{c}\text { No. of } \\
\text { studies }\end{array}$ & $\begin{array}{c}\text { No. of } \\
\text { participants }\end{array}$ & Statistical method & Effect size \\
\hline 1 Participant recruited & 1 & 469 & Risk Ratio (M-H, Fixed, 95\% CI) & $1.26[1.06,1.50]$ \\
\hline
\end{tabular}

Comparison 13. Enhanced recruitment package vs standard recruitment package

\begin{tabular}{lcccc} 
Outcome or subgroup title & $\begin{array}{c}\text { No. of } \\
\text { studies }\end{array}$ & $\begin{array}{c}\text { No. of } \\
\text { participants }\end{array}$ & Statistical method & Effect size \\
\hline 1 Participant recruited & 1 & 6376 & Risk Ratio (M-H, Fixed, 95\% CI) & $0.88[0.65,1.18]$ \\
\hline
\end{tabular}

Comparison 14. Enhanced recruitment package + baseline data over 'phone vs standard recruitment package

\begin{tabular}{lccccc} 
Outcome or subgroup title & $\begin{array}{c}\text { No. of } \\
\text { studies }\end{array}$ & $\begin{array}{c}\text { No. of } \\
\text { participants }\end{array}$ & Statistical method & Effect size \\
\hline 1 Participant recruited & 1 & 6372 & Risk Ratio (M-H, Fixed, 95\% CI) & $0.98[0.74,1.31]$ \\
\hline
\end{tabular}


Comparison 15. Enhanced recruitment package + recruitment at churches vs standard recruitment package

\begin{tabular}{lcccc} 
Outcome or subgroup title & $\begin{array}{c}\text { No. of } \\
\text { studies }\end{array}$ & $\begin{array}{c}\text { No. of } \\
\text { participants }\end{array}$ & Statistical method & Effect size \\
\hline 1 Participant recruited & 1 & 6246 & Risk Ratio (M-H, Fixed, 95\% CI) & $1.37[1.05,1.78]$ \\
\hline
\end{tabular}

Comparison 16. Electronic completion of screening questionnaire vs standard paper completion

\begin{tabular}{lcccc} 
Outcome or subgroup title & $\begin{array}{c}\text { No. of } \\
\text { studies }\end{array}$ & $\begin{array}{c}\text { No. of } \\
\text { participants }\end{array}$ & Statistical method & Effect size \\
\hline 1 Participant recruited & 1 & 292 & Risk Ratio (M-H, Fixed, 95\% CI) & $0.85[0.67,1.07]$ \\
\hline
\end{tabular}

Comparison 17. Oral completion of screening questionnaire vs standard paper completion

\begin{tabular}{lcccc} 
Outcome or subgroup title & $\begin{array}{c}\text { No. of } \\
\text { studies }\end{array}$ & $\begin{array}{c}\text { No. of } \\
\text { participants }\end{array}$ & Statistical method & Effect size \\
\hline 1 Participant recruited & 1 & 219 & Risk Ratio (M-H, Fixed, 95\% CI) & $1.00[0.77,1.29]$ \\
\hline
\end{tabular}

Comparison 18. Home safety questionnaire + trial invitation vs trial invitation

\begin{tabular}{lcccc} 
Outcome or subgroup title & $\begin{array}{c}\text { No. of } \\
\text { studies }\end{array}$ & $\begin{array}{c}\text { No. of } \\
\text { participants }\end{array}$ & Statistical method & Effect size \\
\hline 1 Participant recruited & 1 & 2393 & Risk Ratio (M-H, Fixed, 95\% CI) & $1.37[1.13,1.65]$ \\
\hline
\end{tabular}

Comparison 19. Clinical trial booklet + standard information vs standard information

\begin{tabular}{lcccc} 
Outcome or subgroup title & $\begin{array}{c}\text { No. of } \\
\text { studies }\end{array}$ & $\begin{array}{c}\text { No. of } \\
\text { participants }\end{array}$ & Statistical method & Effect size \\
\hline 1 Participant recruited & 1 & 31 & Risk Ratio (M-H, Fixed, 95\% CI) & $1.28[0.92,1.78]$ \\
\hline
\end{tabular}


Comparison 20. Negative framing of side effects vs neutral framing

\begin{tabular}{lcccc} 
Outcome or subgroup title & $\begin{array}{c}\text { No. of } \\
\text { studies }\end{array}$ & $\begin{array}{c}\text { No. of } \\
\text { participants }\end{array}$ & Statistical method & Effect size \\
\hline 1 Participant recruited & 1 & 60 & Risk Ratio (M-H, Fixed, 95\% CI) & $0.87[0.63,1.20]$ \\
\hline
\end{tabular}

Comparison 21. Positive framing of side effects vs neutral framing

\begin{tabular}{lcccc} 
Outcome or subgroup title & $\begin{array}{c}\text { No. of } \\
\text { studies }\end{array}$ & $\begin{array}{c}\text { No. of } \\
\text { participants }\end{array}$ & Statistical method & Effect size \\
\hline 1 Participant recruited & 1 & 60 & Risk Ratio (M-H, Fixed, 95\% CI) & $0.78[0.55,1.11]$ \\
\hline
\end{tabular}

Comparison 22. Interactive computer presentation of trial information vs audio-taped presentation

\begin{tabular}{lcccc} 
Outcome or subgroup title & $\begin{array}{c}\text { No. of } \\
\text { studies }\end{array}$ & $\begin{array}{c}\text { No. of } \\
\text { participants }\end{array}$ & Statistical method & Effect size \\
\hline 1 Participant recruited & 1 & 100 & Risk Ratio (M-H, Fixed, 95\% CI) & $1.48[1.00,2.18]$ \\
\hline
\end{tabular}

Comparison 23. Writing treatment effect is 'twice as fast' in trial information vs writing 'half as fast'

\begin{tabular}{lcccc} 
Outcome or subgroup title & $\begin{array}{c}\text { No. of } \\
\text { studies }\end{array}$ & $\begin{array}{c}\text { No. of } \\
\text { participants }\end{array}$ & Statistical method & Effect size \\
\hline 1 Participant recruited & 1 & 100 & Risk Ratio (M-H, Fixed, 95\% CI) & $1.62[1.10,2.37]$ \\
\hline
\end{tabular}

Comparison 24. Total information disclosure vs standard disclosure

\begin{tabular}{lcccc} 
Outcome or subgroup title & $\begin{array}{c}\text { No. of } \\
\text { studies }\end{array}$ & $\begin{array}{c}\text { No. of } \\
\text { participants }\end{array}$ & Statistical method & Effect size \\
\hline 1 Participant recruited & 1 & 57 & Risk Ratio (M-H, Fixed, 95\% CI) & $1.13[0.93,1.38]$ \\
\hline
\end{tabular}

